\title{
A dose ranging trial to optimize the dose of rifampin in the treatment of tuberculosis
}

\begin{tabular}{|c|c|}
\hline Journal: & American Journal of Respiratory And Critical Care Medicine \\
\hline Manuscript ID: & Blue-201407-12640C.R2 \\
\hline Manuscript Type: & OC - Original Contribution \\
\hline Date Submitted by the Author: & $\mathrm{n} / \mathrm{a}$ \\
\hline Complete List of Authors: & $\begin{array}{l}\text { Boeree, Martin; Radboud UMC, Lung Diseases; UCCZ Dekkerswald, } \\
\text { Diacon, Andreas; Stellenbosch University, Department of Science and } \\
\text { Technology; TASK Applied Sciences, } \\
\text { Dawson, Rodney; University of Cape Town, Department of Respiratory } \\
\text { Medicine; The Lung Institute, } \\
\text { Narunsky, Kim; University of Cape Town, Department of Respiratory } \\
\text { Medicine; The Lung Institute, } \\
\text { du Bois, Jeannine; TASK Applied Sciences, } \\
\text { Phillips, Patrick; MRC Clinical Trials Unit at UCL, } \\
\text { Gillespie, Stephen; The Medical School University of St Andrews, } \\
\text { Mc Hugh, Timothy; University College London, Centre for Clinical } \\
\text { Microbiology } \\
\text { Hoelscher, Michael; Medical Center of the University of Munich, Division of } \\
\text { Infectious Diseases and Tropical Medicine; German Centre for Infection } \\
\text { Research DZIF, Partner site Munich } \\
\text { Heinrich, Norbert; Medical Center of the University of Munich, Division of } \\
\text { Infectious Diseases and Tropical Medicine; German Centre for Infection } \\
\text { Research DZIF, Partner site Munich } \\
\text { Rehal, Sunita; MRC Clinical Trials Unit at UCL, } \\
\text { van Soolingen, Dick; Radboud University Medical Center, Department of } \\
\text { Medical Microbiology; National Institute for Public Health and the } \\
\text { Environment, National Mycobacteria Reference Laboratory } \\
\text { van Ingen, Jakko; Radboud University Medical Center, Department of } \\
\text { Medical Microbiology } \\
\text { Magis-Escurra, Cecile; Radboud University Medical Center, Department of } \\
\text { Lung Diseases } \\
\text { Burger, David; Radboud University Medical Center, Department of } \\
\text { Pharmacy } \\
\text { Plemper van Balen, Georgette; Radboud University Medical Center, } \\
\text { Department of Lung Diseases } \\
\text { Aarnoutse, Rob; Radboud University Medical Center, Department of } \\
\text { Pharmacy }\end{array}$ \\
\hline Subject Category: & $\begin{array}{l}11.06 \text { Treatment of Tuberculosis or Latent Infection }<\text { MYCOBACTERIAL } \\
\text { DISEASES }\end{array}$ \\
\hline Keywords: & $\begin{array}{l}\text { Antitubercular Agents, Dose-Response Relationship, Drug, } \\
\text { Pharmacokinetics, Drug Therapy, Clinical Trial }\end{array}$ \\
\hline
\end{tabular}


Page 1 of 59
\begin{tabular}{l}
\hline SCHOLARONE" \\
Manuscripts
\end{tabular}

Page 1 of 59
\begin{tabular}{r}
\hline SCHOLARONE \\
Manuscripts
\end{tabular}

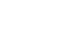

.
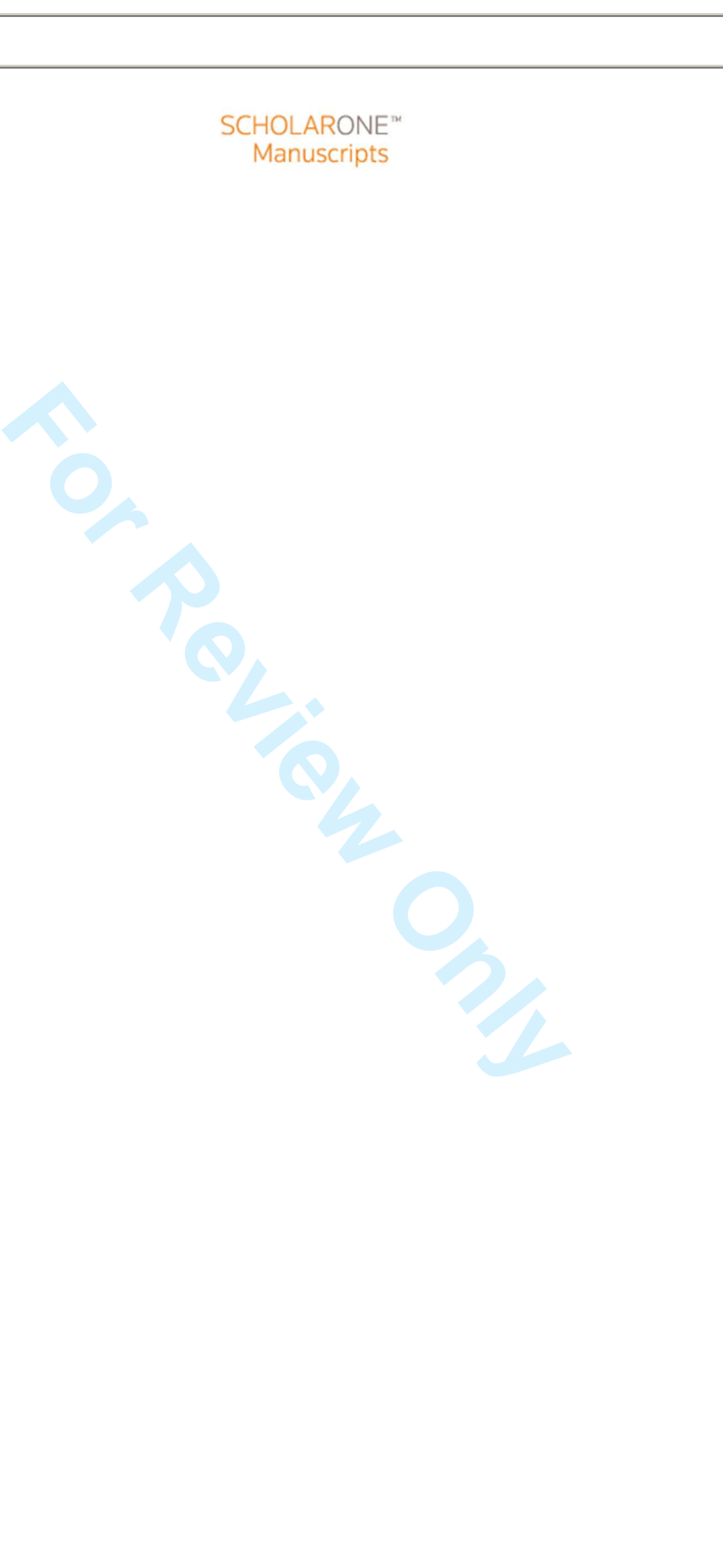


\section{A dose ranging trial to optimize the dose of rifampin in the treatment of tuberculosis}

Martin J. Boeree ${ }^{1,2} *$, Andreas H. Diacon ${ }^{3,4}$, Rodney Dawson ${ }^{5,6}$, Kim Narunsky $^{5,6}$, Jeannine du Bois $^{4}$, Amour Venter ${ }^{3}$, Patrick P.J. Phillips ${ }^{7}$, Stephen H. Gillespie ${ }^{8}$, Timothy D. Mc Hugh ${ }^{9}$, Michael Hoelscher ${ }^{10,11}$, Norbert Heinrich ${ }^{10,11}$, Sunita Rehal ${ }^{7}$, Dick van Soolingen ${ }^{12,13}$, Jakko van Ingen ${ }^{12}$, Cecile Magis-Escurra ${ }^{1}$, David Burger ${ }^{14}$, Georgette Plemper van Balen ${ }^{1}$, Rob E. Aarnoutse $^{14}$

${ }^{1}$ Radboud University Medical Center, Department of Lung Diseases, Nijmegen, the Netherlands

${ }^{2}$ University Centre for Chronic Diseases Dekkerswald, Groesbeek, the Netherlands

${ }^{3}$ Stellenbosch University, Department of Science and Technology, Tygerberg, South Africa,

${ }^{4}$ TASK Applied Sciences, 1 Small Street, Cape Town, ZA 7530, South Africa

${ }^{5}$ University of Cape Town, Department of Respiratory Medicine, Cape Town, South Africa

${ }^{6}$ The Lung Institute, Cape Town, South Africa

${ }^{7}$ MRC Clinical Trials Unit at University College London, London, United Kingdom

${ }^{8}$ The Medical School University of St Andrews, St Andrews Fife, UK KY16 9TF, United Kingdom

${ }^{9}$ University College London, Centre for Clinical Microbiology, London, United Kingdom 
${ }^{10}$ University of Munich, Department for Infectious Diseases and Tropical Medicine, Munich, Germany

${ }^{11}$ German Centre for Infection Research DZIF, Partner site Munich, Munich, Germany

${ }^{12}$ Radboud University Medical Center, Department of Medical Microbiology, Nijmegen, the Netherlands

${ }^{13}$ National Institute for Public Health and the Environment, National Mycobacteria Reference Laboratory, PO Box 1, Bilthoven, NL 3720 BA, the Netherlands

${ }^{14}$ Radboud University Medical Center, Department of Pharmacy, Nijmegen, the Netherlands

\section{* Corresponding author}

Martin J. Boeree, MD, PhD, Radboud University Medical Center, Department of Lung Diseases, PO Box 9101, Nijmegen, NL 6500 HB, the Netherlands and University Centre for Chronic Diseases Dekkerswald, Po Box 66, 6560 AB, Groesbeek, the Netherlands, T + 3124 6859293, F+31 24 6859290, E: Martin.Boeree@radboudumc.nl

\section{Author contributions:}

$M B, A D, R D, T M c H, M H, N H, D v S, J v l, C M, D B, S G$ and RA contributed to conception, design, and the trial protocol, $M B, A D, R D, K N, J d B, A V, G P v B$ and $R A$ collected the data, $M B, P P, S G$, SR and RA performed and supervised data analysis, MB wrote the draft manuscript, and all authors critically reviewed the several and the final drafts of the manuscript 


\section{Funding:}

The study was funded by the EDCTP (European \& Developing Countries Clinical Trials Partnership), NACCAP (Netherlands-African partnership for Capacity development and Clinical interventions Against Poverty-related diseases) and the Bill \& Melinda Gates Foundation.

Running Title: The right dose of rifampin

Descriptor: 11.6 Treatment of Tuberculosis or Latent Infection

Total word count for manuscript body: 3121

\section{At a Glance Commentary:}

Scientific Knowledge on the Subject: The currently used dose of $10 \mathrm{mg}$ rifampin/kg for the treatment of drug sensitive tuberculosis is probably too low. Data in vitro, in mice and in humans indicate that higher doses of rifampin may shorten the duration of treatment and decrease the emergence of resistance. 


\section{What This Study Adds to the Field:}

Higher doses of rifampin up to $35 \mathrm{mg} / \mathrm{kg}$ were safe and well tolerated for two weeks. The higher doses of rifampin achieved up to 10 -fold higher average exposures in plasma. There is an indication of increased efficacy in the higher dosing groups because of a greater estimated fall in bacterial load. These findings offer evidence for a definitive answer to the question what the right dose of rifampin is.

This article has an online data supplement, which is accessible from this issue's table of content online at www.atsjournals.org" 


\section{ABSTRACT}

Rationale: Rifampin at a dose of $10 \mathrm{mg} / \mathrm{kg}$ was introduced in 1971 based on pharmacokinetic, toxicity and cost considerations. Available data in mice and humans showed that an increase in dose may shorten the duration of tuberculosis treatment. Objectives: To evaluate the safety and tolerability, the pharmacokinetics and the extended early bactericidal activity of increasing doses of rifampin.

Methods: Patients with drug-susceptible tuberculosis were enrolled into a control group of 8 patients receiving the standard dose of $10 \mathrm{mg} / \mathrm{kg}$ rifampin, followed by consecutive experimental groups with 15 patients each receiving rifampin $20 \mathrm{mg} / \mathrm{kg}, 25 \mathrm{mg} / \mathrm{kg}, 30 \mathrm{mg} / \mathrm{kg}$ and $35 \mathrm{mg} / \mathrm{kg}$, respectively, for 14 days. In all patients isoniazid, pyrazinamide and ethambutol were added in standard doses for the second 7 days of treatment. Safety, pharmacokinetics of rifampin, and fall in bacterial load were assessed.

Measurements and Main Results: Grade 1 and 2 adverse events were equally distributed between the five dose groups; there were 5 grade 3 events of which 1 was a possibly related hepatotoxicity. Areas under the time-concentration curves and peak serum concentrations of rifampin showed a more than proportional increase with dose. The daily fall in bacterial load over 14 days was $0.176,0.168,0.167,0.265$, and $0.261 \log _{10} \mathrm{CFU} / \mathrm{ml}$ sputum in the 10 , $20,25,30$ and $35 \mathrm{mg} / \mathrm{kg}$ groups respectively.

Conclusions: Two weeks of rifampin up to $35 \mathrm{mg} / \mathrm{kg}$ was safe and well tolerated. There was a non-linear increase in exposure to rifampin without an apparent ceiling effect and a greater estimated fall in bacterial load in the higher dosing groups. (ClinicalTrials.gov number

NCT01392911) 
Word count abstract: 258

\section{INTRODUCTION}

Rifampin is one of the pivotal drugs for the treatment of tuberculosis. The US Food and Drug Administration approved rifampin in 1971 and several trials showed that rifampin containing-regimens were very effective: in combination with pyrazinamide, it became possible to shorten the duration of treatment to six months.(1) Six-month rifampincontaining regimens are now the standard of care and recommended by national and international bodies including the American Thoracic Society and the World Health Organization. Virtually all of the studies that underpin these recommendations used a dose of $10 \mathrm{mg}$ rifampin $/ \mathrm{kg}$.(2) A dose finding study with an assessment of the maximum tolerated dose(3) was never performed. The recommended dose was chosen on the basis that it was effective at the lowest cost and limited by fear of adverse effects.

There is an accumulating body of evidence that suggest that higher doses of rifampin may be more effective and lead to significant shortening of the duration of tuberculosis treatment. In vitro experiments in a pharmacokinetic-pharmacodynamic model of tuberculosis showed that higher doses of rifampin kill the bacteria more rapidly and prevent the emergence of resistance to rifampin(4). Mouse experiments showed increased killing of bacteria and enhanced sterilizing activity with higher doses, resulting in a significant shortening of treatment duration.(5-7) Additionally, an estimation of maximum tolerated dose in mice was shown to be $160 \mathrm{mg}$ rifampin/ $\mathrm{kg}(7)$. Studies of monotherapy with rifampin in tuberculosis patients demonstrated that a moderate increase in the dose of rifampin leads to a steeper 
fall of bacterial load over time.(8-10) A systematic review of 14 randomized controlled trials that evaluated higher doses up to $20 \mathrm{mg}$ rifampin/kg in humans, most of them performed before 1980, suggests that higher doses of rifampin result in improved culture conversion rates.(11) A trial in pulmonary tuberculosis patients in Indonesia comparing $450 \mathrm{mg}$ rifampin $(10 \mathrm{mg} / \mathrm{kg})$ to $600 \mathrm{mg} / \mathrm{kg}(13 \mathrm{mg} / \mathrm{kg})$ rifampin showed a nonlinear, more than proportional increase of pharmacokinetic exposure.(12)

The adverse effects of rifampin at the standard dose are well known, because of years of worldwide use since its introduction.(13) Yet, the relationship between dose and adverse events is not well established and may be either toxic with a clear relation or idiosyncratic without such a relation.(14) There have been trials and case series that used higher doses of rifampin in tuberculosis and other infections such as brucellosis, leishmaniasis, Legionnaires' disease, and bone and joint infections $(2,15-19)$ without severe adverse effects. Some events, such as the flu like syndrome are likely related to intermittent dosing.(20)

If increasing rifampin may be more effective and could shorten therapy there is an urgent need to know the optimum dose. We performed a study in tuberculosis patients, therefore, to establish the maximum tolerated dose, to assess the incidence and severity of adverse events, to describe the pharmacokinetics and to measure the bactericidal effect of higher doses of rifampin.

Some of the results of these studies have been previously reported in the form of an abstract. (21) 


\section{METHODS}

\section{Patients}

Adults (18 to 65) with newly diagnosed, previously untreated, sputum smear-positive uncomplicated pulmonary tuberculosis and with no medical contraindications (see Table E1 in the online data supplement) were included in the study. For HIV positive subjects a CD4 count of $\geq 350$ cells was an additional inclusion criterion. Patients were hospitalized in one of two study sites in Cape Town, South Africa.

\section{Study design}

We performed an open-label phase II multiple dose ranging study to evaluate safety, tolerability, pharmacokinetics and extended early bactericidal activity of increasing doses of rifampin. All patients received a specified dose of rifampin for 14 days, given in monotherapy for the first 7 days and supplemented with standard doses of isoniazid 5 $\mathrm{mg} / \mathrm{kg}$, pyrazinamide $25-30 \mathrm{mg} / \mathrm{kg}$ and ethambutol $15-20 \mathrm{mg} / \mathrm{kg}$ for the last 7 days. The patients then continued standard tuberculosis treatment (Figure 1) and had visits at 3 and 12 weeks for clinical assessment and sputum culture for susceptibility testing.

The first 8 patients were enrolled in a control cohort receiving $10 \mathrm{mg}$ rifampin $/ \mathrm{kg}$. Subsequently, patients were enrolled in consecutive intervention cohorts of 15 patients each. The first cohort received rifampin at a dose of $20 \mathrm{mg} / \mathrm{kg}$. The second cohort received $25 \mathrm{mg}$ rifampin/ $\mathrm{kg}$, the third $30 \mathrm{mg}$ rifampin $/ \mathrm{kg}$ and the last cohort received $35 \mathrm{mg}$ 
rifampin/kg. Of note, the consecutive dose increases for rifampin were relatively small, considering the non-linear pharmacokinetics of rifampin, which means that an increase in dose may result in an unpredictable, disproportionally larger increase in exposure.(22)

After completion of follow-up by all subjects in each cohort, the Trial Steering Committee, reviewed all of the safety data for the cohort before the first patient in the next cohort was enrolled. Two subjects experiencing a grade 3 adverse event assessed as probably or definitely related to administration of high dose rifampin, or one subject experiencing a grade 4 or 5 adverse event assessed as definitely related to rifampin, would lead to a meeting of the Trial Steering Committee to discuss the continuation or termination of the study.(23)

The study protocol was approved by local ethical review boards and by the Medical Control Council of South Africa and was conducted according to Good Clinical Practice standards. All patients provided written informed consent before enrolment in the study.

The innovative design of this study differs from a classical "early bactericidal activity" study intended for comparison.

Drug management

During the 7 days of rifampin monotherapy, patients received rifampin administered as capsules Rifadin ${ }^{\circledR}(150 \mathrm{mg}, 300 \mathrm{mg}$ and /or $600 \mathrm{mg}$ ) from Sanofi-Aventis. Combination therapy of rifampin, isoniazid, pyrazinamide and ethambutol during the subsequent 7 days was administered in the form of the fixed dose combination (FDC) Rifafour ${ }^{\circledR}$ e-275 from Sanofi-Aventis, containing $150 \mathrm{mg}$ rifampin, $75 \mathrm{mg}$ isoniazid, $400 \mathrm{mg}$ pyrazinamide and $275 \mathrm{mg}$ ethambutol per tablet. The subjects in the control group received only standard 
Rifafour $^{\circledR}$ e-275 treatment. The subjects in the other dosing groups received additional Rifadin ${ }^{\circledast}$ to reach the same pre-defined rifampin dose as administered in the monotherapy period. The exact amount of Rifafour ${ }^{\circledR} \mathrm{e}-275$ tablets and Rifadin ${ }^{\circledR}$ capsules was dependent on the dosing group of the patient and the patient's weight before start of the study. Daily treatment bottles for all 14 days were prepared in advance and checked by pharmacists or site staff members who were licensed for dispensing.

\section{Safety and tolerability}

The primary objective of this study was to assess the maximum tolerated dose, which is defined as the dose below that producing unacceptable but reversible toxicity. Tolerability is an aspect of safety and used to indicate how well a patient is able to endure treatment such that adverse events do not result in the discontinuation of treatment(3).

Symptoms assessments, physical examination, including vital signs, were performed on a daily base. Haematological, renal and liver function tests, glucose, uric acid and urinalysis and electrocardiography were scheduled at baseline and days $1,3,6,10,14$ and 21 with appropriately narrow window periods. Adverse events were graded according to the US National Institute of Health Common Terminology Criteria for Adverse Events 4.0.(24) Patients with serious adverse events were followed up until resolution of the event. Events were assessed as unrelated, possibly or definitely related by site investigators (see Table E2 in the online data supplement).

\section{Pharmacokinetics}

Blood samples were taken on day 7 and day 14 with a standardized meal for a full pharmacokinetics curve. Total (protein-bound plus unbound) plasma concentrations of 
rifampin were measured at the Department of Pharmacy of the Radboud University Medical center, Nijmegen, the Netherlands, using a validated Ultra Performance Liquid Chromatography method with ultraviolet detection, derived from a previously described assay.(12) Noncompartmental pharmacokinetic analysis was performed with Winnonlin version 5.3 (Pharsight Corp., Mountain View, California US) to yield pharmacokinetic parameters, including the area under the plasma concentration-time curve $\left(A \cup C_{0-24 h}\right.$ or total exposure) and highest observed plasma concentration $\left(C_{\max }\right)$, as described before.(12)

\section{Antimycobacterial activity}

Spot sputum samples were collected before enrolment, at day 19 and after 12 weeks. The samples were prepared for direct microscopy, stained with the auramine 0 method and presence of acid fast bacilli was scored using the IUATLD/WHO grading. Pooled overnight (16 hours) samples were collected at baseline, daily to day 7, days 9 and 14. Each sample was diluted and cultured in quadruplicate on selective Middlebrook 7H11 agar plates. Counts of colony forming units (CFU) were done after a minimum of 21 days of incubation to assess the fall of CFU over time. $(25,26)$ In addition, the samples were processed for culture in liquid broth medium according to the mycobacterial growth indicator tube (Bactec MGIT960) system. Time-to-positivity (TTP) was determined for each sample to assess the change in TTP over time. The remainder of the baseline samples were processed to determine susceptibility tests and an Accuprobe identification (Gen-Probe ${ }^{\circledR}$ ) test was carried out to confirm presence of M. tuberculosis complex. All microbiological testing was performed in the Department of Medical Biochemistry, Faculty of Medicine and Health Sciences, Stellenbosch University, Cape Town, South Africa. 


\section{Statistical analysis}

This was a descriptive study with no inferential statistics or hypothesis testing. The planned sample size of 15 patients in each group is in keeping with other trials of this type and accounts for the site conservative estimate of 3 dropouts per group.(3) Safety was expressed as incidence of adverse events by severity and relatedness. The AUCO-24h and Cmax of rifampin at days 7 and 14 were presented as geometric means by study group. The distribution of TTP on MGIT was positively skewed with log-transformed TTP more closely following a symmetric normal distribution. Mixed effects models with visit day as a discrete random effect were used to estimate the mean logCFU and logTTP in each treatment arm at each visit to describe the data. LogCFU of 1 or TTP of 42 days was used for negative cultures in this analysis. We found an unexpectedly high number of negative cultures for the short treatment duration. These data points would usually be excluded with standard regression methods due to the quantitative measure of logCFU or TTP being below or above the limit of detection. In order to include these censored observations, Tobit regression(27) was used to estimate the 14-day early bactericidal activity, accounting for negatives cultures using a lower limit of detection censoring for logCFU of 1 and an upper limit for TTP of 42 days. Separate models were fitted for each patient with parameter estimates summarised by treatment group using a random effects model accounting for within- and between- patient variability. Linear regression was used to explore the relationship between 14-day early bactericidal activity and each of actual dose received in $\mathrm{mg}$, actual dose received in $\mathrm{mg} / \mathrm{kg}$ 
and exposures achieved $\left(\mathrm{AUC}_{0-24}\right.$ and $\left.\mathrm{C}_{\max }\right)$ comparing models using the proportion of variation explained, $\mathrm{R}^{2}$.

\section{RESULTS}

\section{Patients}

A total of 68 culture positive pulmonary tuberculosis patients were recruited between June 2011 and April 2012 with the last patient completing follow-up in August 2012. Patient characteristics are shown in Table 1.

\section{Safety/tolerability}

The stopping criteria were not met and the Trial Steering Committee recommended that the trial continued after data safety review at the end of each cohort. None of the patients discontinued or were withdrawn from the study. There were a total of 163 adverse events: 128 grade 1, 30 grade 2 , and 5 grade 3 adverse events. No grade 4 and 5 adverse events occurred. 53 adverse events were unrelated to rifampin, 102 were "possibly" related and 8 were assessed to be "definitely" related to rifampin (Table 2).

The most common adverse events related to monotherapy with rifampin were abdominal pain, vomiting, headache, and pruritus. The most common adverse events related to the combination treatment with rifampin, isoniazid, pyrazinamide and ethambutol were vomiting, headache, hyperuricaemia, pain in the extremities and pruritus. These adverse events occurred in all groups and were not attributable to a specific dose group. 


\section{Pharmacokinetics}

The average $\mathrm{AUC}_{0-24}$ and $\mathrm{C}_{\max }$ values of rifampin at day 14 are presented in Table 3. Upon doubling the dose of rifampin from $10 \mathrm{mg} / \mathrm{kg}$ to $20 \mathrm{mg} / \mathrm{kg}$, the geometric mean $\mathrm{AUC}_{0-24}$ of rifampin increased more than four-fold, which reflects a more than dose-proportional increase of exposure with the dose. No ceiling in rifampin $A U C_{0-24}$ or flattening of the relationship between dose administered and $\mathrm{AUC}_{0-24}$ achieved was observed. Strong increases in average rifampin Cmax with the dose were also observed (Table 3). Of note, large interindividual variability in $\mathrm{AUC}_{0-24 \mathrm{~h}}$ and $\mathrm{C}_{\max }$ was observed (Table 3 and Figure 2), yet the minimum exposure recorded in each group (either in terms of $A \cup C_{0-24 h}$ or $C_{\text {max }}$ ) increased with the dose administered.

\section{Antimycobacterial activity}

One patient in the $20 \mathrm{mg} / \mathrm{kg}$ group was negative on solid media at all but one sample and these data were therefore removed from all analyses. The fall in bacterial load in sputum over time expressed as CFU and TTP is summarized in Figure 3. The highest doses of 30 and $35 \mathrm{mg} / \mathrm{kg}$ show highest 14-day early bactericidal activity on both CFU and TTP (Figure 4). There was no clear biphasic curve from days 7-14 after which the other drugs, including isoniazid were added. At 14 days, 8 of 14 patients in the $35 \mathrm{mg} / \mathrm{kg}$ group were culture negative on solid media as compared to 3 of 8 in the control group, 5 of 14 in the $20 \mathrm{mg} / \mathrm{kg}$ group, 0 of 15 in the $25 \mathrm{mg} / \mathrm{kg}$ and 2 of 15 in the $30 \mathrm{mg} / \mathrm{kg}$ group.

$\mathrm{AUC}_{0-24 \mathrm{~h}}$ at day 14 was a better predictor of 14-day early bactericidal activity on CFU $\left(R^{2}=0.12\right)$ than dose in $\mathrm{mg} / \mathrm{kg}$ received $\left(\mathrm{R}^{2}=0.06\right)$ or the dose in $\mathrm{mg}\left(\mathrm{R}^{2}=0.05\right)$, although the proportion of explained variance was low. $\mathrm{AUC}_{0-24 \mathrm{~h}}$ was a marginally better predictor of $14-$ 
day early bactericidal activity on TTP $\left(R^{2}=0.19\right)$ than dose in $\mathrm{mg} / \mathrm{kg}$ received $\left(R^{2}=0.18\right)$ or the dose in $m g\left(R^{2}=0.12\right)$.

\section{DISCUSSION}

This study shows that doses of rifampin that are considerably higher than the standard dose are safe and well tolerated. As accumulating evidence indicates that higher doses of and increased exposures to rifampin are more efficacious in tuberculosis treatment, $(5-7,10,11$, $28,29)$ we believe that this finding may change the landscape of treatment for drug susceptible tuberculosis and may permit shortening of the duration of treatment, as rifampin is a very strong sterilizer. In addition, there is evidence that an important driver behind the emergence of multidrug-resistant tuberculosis is low exposures of especially rifampin caused by inter-individual pharmacokinetic variability. $(4,30,31)$ The current standard dose of rifampin used in the last 40 years is probably considerably too low in many patients.

The primary objective of this study was to estimate the maximum tolerated dose of rifampin and it was significant that dose-limiting toxicities were not found at the highest administered dose of $35 \mathrm{mg} / \mathrm{kg}$ daily. Higher doses than $35 \mathrm{mg} / \mathrm{kg}$ were not planned before the study, as very high exposures to rifampin were anticipated at this dose and the study did not have unrestricted funding.

The pharmacokinetic behaviour of rifampin over the range of increasing doses was more than dose-proportional, "super-proportional". The average $\mathrm{AUC}_{0-24}$ at $35 \mathrm{mg} / \mathrm{kg}$ was almost 
10 -fold higher than the average exposure at $10 \mathrm{mg} / \mathrm{kg}$ rifampin. This phenomenon was previously described in other studies for lower doses. $(12,22)$ We did not observe a ceiling effect as was reported in the pharmacokinetics of one of the other promising rifamycins, rifapentine.(32) Importantly, apart from average exposures, the lowest observed $\mathrm{AUC}_{0-24 \mathrm{~h}}$ and $C_{\max }$ values also increased, with almost every dose step (Table 3 and Figure 2). This is what we aimed for, as it is probably the lowest exposures that cause treatment failures and relapses thereby preventing treatment shortening. In addition, these low exposures may favor the emergence of resistance. $(4,30,31)$ We showed, however, that there was a large inter-individual variation in pharmacokinetics (Figure 2). This is a warning for further studies of high doses of rifampin, as individual exposures may be much higher than our observed means. This may have a beneficial effect in terms of efficacy, but may also cause an increased risk of toxicity.

There was a greater estimated fall in bacterial load in the higher dosing groups dose as measured by a larger fall in CFUs over time and by a more rapid increase in TTP over time. This study was not powered for efficacy and these differences were not statistically significant. Although this result is encouraging, the finding may not necessarily indicate increased efficacy in terms of treatment failure and relapse, the definitive patient-relevant outcomes and phase III endpoints. In mouse models, however, there is evidence that higher doses of rifampin sterilize and cure the mice in a shorter period of time.(5-7) Additionally, in a recent clinical trial in Indonesian tuberculous meningitis patients higher doses of rifampin (around $13 \mathrm{mg} / \mathrm{kg}$ intravenously as compared to around $10 \mathrm{mg} / \mathrm{kg}$ orally) led to a decreased 6 months mortality of roughly $50 \% .(33)$ 
By design, small numbers of patients selected on the basis of very strict criteria were treated for only a short period of time with higher doses of rifampin. Therefore, our findings need to be confirmed in longer phase II studies with less narrow inclusion criteria and adequate patients numbers before being tested in a phase III study. Currently, two studies have started with this objective. The first randomized controlled trial has recently finished enrolment (ClinicalTrials.gov NCT00760149) and compared a control group with the standard tuberculosis regimen with two groups of $15 \mathrm{mg}$ rifampin/ $/ \mathrm{kg}$ and $20 \mathrm{mg}$ rifampin/kg combined with isoniazid, pyrazinamide and ethambutol for two months in groups of 50 patients each. The second study with a multi arm multi stage (MAMS) design performed within the PanACEA consortium (ClinicalTrials.gov NCT01785186) compares a standard control group with a group on $20 \mathrm{mg}$ rifampin $/ \mathrm{kg}$ combined with moxifloxacin, isoniazid and pyrazinamide, a group with $20 \mathrm{mg}$ rifampin/kg combined with the new compound SQ109(34) and isoniazid and pyrazinamide, and a group with $35 \mathrm{mg}$ rifampin/ $\mathrm{kg}$ combined with isoniazid, pyrazinamide and ethambutol for three months. A further two month study is evaluating $15 \mathrm{mg}$ rifampin/kg and $20 \mathrm{mg}$ rifampin/kg in Peru (ClinicalTrials.gov NCT01408914). Depending on the results of these trials, we are planning to extend the study in this paper and increase the dose until the actual maximum tolerated dose is reached. In conclusion, higher doses of rifampin up to $35 \mathrm{mg} / \mathrm{kg}$ were safe and well tolerated for two weeks. The higher doses of rifampin achieved up to 10-fold higher average exposures in plasma, due to nonlinear "super-proportional" pharmacokinetic behaviour. The greater estimated fall in bacterial load measured by CFUs and TTP suggests an increased efficacy in the higher dosing groups supporting the idea that this critical drug is being administered at too low a dose. With the results of phase IIB studies currently underway that further 
examine these higher dose, we should look forward to a pivotal phase III trial to definitely answer the question what the right dose of rifampin is.

\section{Acknowledgments}

We thank Prof. Peter R. Donald from the Stellenbosch University, Tygerberg, South Africa and Prof. Paul A. Willcox, University of Cape Town, Cape Town, South Africa for their role in the Trial Steering Committee. 


\begin{tabular}{|c|c|c|c|c|}
\hline All & $10 \mathrm{mg}$ & $20 \mathrm{mg}$ & $25 \mathrm{mg}$ & $30 \mathrm{mg}$ \\
\hline Subjects & RIF/kg & RIF/kg & RIF/kg & RIF/kg \\
\hline
\end{tabular}

$\mathrm{N}$

68

8

15

15

15

15

Age (yr)

\begin{tabular}{lrrrrrr} 
Median & 30.5 & 27.5 & 27.0 & 25.0 & 40.0 & 37.0 \\
Range & $18-59$ & $19-49$ & $18-46$ & $19-46$ & $19-59$ & $21-59$ \\
\hline
\end{tabular}

Weight (kg)

\begin{tabular}{|c|c|c|c|c|c|c|}
\hline Median & 53.6 & 56.9 & 52.5 & 52.8 & 54.0 & 57.0 \\
\hline Range & $40.2-84.2$ & $46.8-64.9$ & $41.8-62.7$ & $40.2-67.9$ & $45.7-84.2$ & $40.5-74.0$ \\
\hline
\end{tabular}

Body-Mass Index (kg/m^2)

\begin{tabular}{lcccccr}
\hline Median & 19.4 & 20.5 & 18.4 & 19.3 & 20.9 & 19.5 \\
Range & $14.7-30.9$ & $15.8-26.3$ & $16.8-26.2$ & $15.1-25.2$ & $16.4-30.9$ & $14.7-25.2$ \\
\hline
\end{tabular}

Male sex no.

$48(71)$

$6(75)$

$11(73)$

$10(67)$

$11(73)$

$10(67)$

Race -no (\%)

\begin{tabular}{|c|c|c|c|c|c|c|}
\hline Black & $28(41)$ & $3(38)$ & 7 (47) & $4(27)$ & $9(60)$ & $5(33)$ \\
\hline Coloured & 40 (59) & $5(63)$ & $8(53)$ & $11(73)$ & $6(40)$ & 10 (67) \\
\hline
\end{tabular}

HIV-positive (\%) 1(1,5)

$1(13)$

Baseline log10CFU/mI median

\begin{tabular}{cccccc}
\hline (range) & 4.88 & 4.00 & 5.39 & 4.58 & 4.39 \\
& $(2.15-5.85)$ & $\begin{array}{c}\text { (negative*-5.82) } \\
(3.70-6.38)\end{array}$ & $\begin{array}{c}(2.68-6.25) \\
(2.86-5.82)\end{array}$ \\
Baseline TTP / days median & 6.04 & 7.35 & 6.75 & 8.08 & 8.22 \\
\hline (range) & $(4.15-12.17)$ & $(4.44-13.33)$ & $(5.00-10.69)$ & $(4.81-13.46)$ & $(4.75-20.04)$
\end{tabular}

Table1. Demographic and baseline characteristics at inclusion. * One patient on $20 \mathrm{mg} / \mathrm{kg}$ group was negative on solid media at all but one visit and their data was therefore removed from all analyses. 


\begin{tabular}{|c|c|c|c|c|c|c|c|}
\hline Group & Total & \multicolumn{2}{|c|}{ Grade 1 } & \multicolumn{2}{c|}{ Grade 2 } & \multicolumn{2}{c|}{ Grade 3 * } \\
\hline Relatedness & & $\begin{array}{c}\text { Possibly } \\
\text { related }\end{array}$ & Related & $\begin{array}{c}\text { Possibly } \\
\text { related }\end{array}$ & Related & $\begin{array}{c}\text { Possibly } \\
\text { related }\end{array}$ & Related \\
\hline $\begin{array}{c}10 \mathrm{mg} / \mathrm{kg} \\
\text { (control) }\end{array}$ & 7 & 0 & 0 & 0 & 0 & 0 & 0 \\
\hline $\begin{array}{c}20 \mathrm{mg} / \mathrm{kg} \\
\mathrm{RIF}\end{array}$ & 39 & 21 & 1 & 4 & 0 & 2 & 0 \\
\hline $\begin{array}{c}25 \mathrm{mg} / \mathrm{kg} \\
\mathrm{RIF}\end{array}$ & 24 & 11 & 2 & 2 & 0 & 0 & 0 \\
\hline $\begin{array}{c}30 \mathrm{mg} / \mathrm{kg} \\
\mathrm{RIF}\end{array}$ & 39 & 21 & 3 & 4 & 0 & 1 & 0 \\
\hline $\begin{array}{c}35 \mathrm{mg} / \mathrm{kg} \\
\text { RIF }\end{array}$ & 54 & 27 & 2 & 9 & 0 & 0 & 0 \\
\hline \begin{tabular}{c} 
Total \\
\hline
\end{tabular} & 163 & 80 & 8 & 19 & 0 & 3 & 0 \\
\hline
\end{tabular}

Table 2. Possibly related and definitely related adverse events per grade and per dose group *Among the grade 3 events there was a case of transient hyperkalemia of $6.1 \mathrm{mmol} / \mathrm{L}$ in the $20 \mathrm{mg} / \mathrm{kg} \mathrm{RIF}$ group that reoccurred in the same patient in week 3 (counted as two events). Potassium values normalized with no specific measures and no ECG changes were recorded. In the $30 \mathrm{mg} / \mathrm{kg}$ RIF group there was one grade 3 unrelated pleural effusion and a possibly related elevation of transaminase more than five times the upper limit of normal, which normalized spontaneously after repeat measurements. No grade 4 or grade 5 events were observed. 


\begin{tabular}{|l|l|l|}
\hline Group & $\mathrm{AUC}_{0-24 \mathrm{~h}}\left(\mathrm{~h}^{*} \mathrm{mg} / \mathrm{L}\right){ }^{*}$ & $\mathrm{C}_{\max }(\mathrm{mg} / \mathrm{L}) \#$ \\
\hline $10 \mathrm{mg} / \mathrm{kg}$ (control) & $26.3(21.3-40.9)$ & $7.4(6.1-9.9)$ \\
\hline $20 \mathrm{mg} / \mathrm{kg}$ & $113(77.5-162)$ & $21.6(16.0-31.9)$ \\
\hline $25 \mathrm{mg} / \mathrm{kg}$ & $135(91.5-228)$ & $25.1(16.3-34.6)$ \\
\hline $30 \mathrm{mg} / \mathrm{kg}$ & $190(84.7-436)$ & $33.1(17.6-55.8)$ \\
\hline $35 \mathrm{mg} / \mathrm{kg}$ & $235(166-321)$ & $35.2(28.6-44.2)$ \\
\hline
\end{tabular}

Table 3. Steady state PK of RIF (day 14) Geometric means and range *AUC ${ }_{0-24 h}$ : area under the time versus concentration curve up to $24 \mathrm{~h}$ post dose, $\mathrm{C}_{\max }$ : peak plasma concentration

\# Serial venous blood samples were taken just prior to and at $0.5,1,1.5,2,3,4,6,8,12,16$ and 24 hours after the investigational products were taken under direct supervision and with a standardized meal 


\section{Legends Figures}

Figure 1. Schematic overview of the study design

In each study group, monotherapy of rifampin for 7 days was administered using Rifadin ${ }^{\circledR}$ from Sanofi-Aventis in $150 \mathrm{mg}$ capsules, $300 \mathrm{mg}$ tablets or $600 \mathrm{mg}$ tablets. The combination of capsules and tablets for each patient was adjusted to achieve the correct dose by weight. In the subsequent period of 7 days, patients received a fixed dose combination tablet Rifafour ${ }^{\circledR}$ e-275, containing 150 mg rifampin, 75 mg isoniazid, 400 mg pyrazinamide and $275 \mathrm{mg}$ ethambutol, combined with additional rifampin (i.e. Rifadin ${ }^{\circledR}$ ) to reach the same pre-defined rifampin dose in $\mathrm{mg} / \mathrm{kg}$ as administered in the monotherapy period. Starting from day 15 the patients were administered Rifafour ${ }^{\circledR}$ e- 275 only. All study medication was taken in the morning with a light breakfast and a glass of water. Administration of tuberculosis drugs was witnessed by site staff and a hand-andmouth procedure was performed to check for drug intake at every occasion.

Figure 2. Distribution of exposure to rifampin $\left(A \cup C_{0-24 h}\right)$ at day 14 in the various rifampin dosing groups. The reference line mimics a linear relationship.

Figure 3. Fitted estimates of differences from mean baseline $\log _{10} \mathrm{CFU}$ (upper panel) and $\log _{10} \mathrm{TTP} / \mathrm{ml}$ (lower panel) by visit and treatment arm

Figure 4. Early bactericidal activity of rifampin based on CFU (upper panel) and TTP (lower panel) per day 


\section{REFERENCES}

1. East African and Medical Research Councils. Controlled clinical trial of short-course (6-month) regimens of chemotherapy for treatment of pulmonary tuberculosis. Lancet 1972;1:1079-1085.

2. van Ingen J, Aarnoutse RE, Donald PR, Diacon AH, Dawson R, Plemper van Balen G, Gillespie $\mathrm{SH}$, Boeree MJ. Why do we use $600 \mathrm{mg}$ of rifampicin in tuberculosis treatment? Clinical infectious diseases : an official publication of the Infectious Diseases Society of America 2011;52:e194-199.

3. Modi M. Dose-finding studies in phase $i$ and estimation of maximally tolerated dose. In: Ting N, editor. Dose finding in drug development: Springer New York; 2006. p. 30-48.

4. Gumbo T, Louie A, Deziel MR, Liu W, Parsons LM, Salfinger M, Drusano GL. Concentrationdependent mycobacterium tuberculosis killing and prevention of resistance by rifampin.

Antimicrobial agents and chemotherapy 2007;51:3781-3788.

5. Jayaram R, Gaonkar S, Kaur P, Suresh BL, Mahesh BN, Jayashree R, Nandi V, Bharat S, Shandil RK, Kantharaj E, Balasubramanian V. Pharmacokinetics-pharmacodynamics of rifampin in an aerosol infection model of tuberculosis. Antimicrobial agents and chemotherapy 2003;47:2118-2124.

6. Rosenthal IM, Tasneen R, Peloquin CA, Zhang M, Almeida D, Mdluli KE, Karakousis PC, Grosset JH, Nuermberger EL. Dose-ranging comparison of rifampin and rifapentine in two pathologically distinct murine models of tuberculosis. Antimicrobial agents and chemotherapy 2012;56:4331-4340.

7. de Steenwinkel JE, Aarnoutse RE, de Knegt GJ, ten Kate MT, Teulen M, Verbrugh HA, Boeree MJ, van Soolingen D, Bakker-Woudenberg IA. Optimization of the rifampin dosage to improve the therapeutic efficacy in tuberculosis treatment using a murine model. American journal of respiratory and critical care medicine 2013;187:1127-1134.

8. Jindani A, Aber VR, Edwards EA, Mitchison DA. The early bactericidal activity of drugs in patients with pulmonary tuberculosis. The American review of respiratory disease 1980;121:939-949. 
9. Jindani A, Dore CJ, Mitchison DA. Bactericidal and sterilizing activities of antituberculosis drugs during the first 14 days. American journal of respiratory and critical care medicine 2003;167:1348-1354.

10. Diacon AH, Patientia RF, Venter A, van Helden PD, Smith PJ, Mcllleron H, Maritz JS, Donald PR. Early bactericidal activity of high-dose rifampin in patients with pulmonary tuberculosis evidenced by positive sputum smears. Antimicrobial agents and chemotherapy 2007;51:2994-2996. 11. Steingart KR, Jotblad S, Robsky K, Deck D, Hopewell PC, Huang D, Nahid P. Higher-dose rifampin for the treatment of pulmonary tuberculosis: A systematic review. The international journal of tuberculosis and lung disease : the official journal of the International Union against Tuberculosis and Lung Disease 2011;15:305-316.

12. Ruslami R, Nijland HM, Alisjahbana B, Parwati I, van Crevel R, Aarnoutse RE. Pharmacokinetics and tolerability of a higher rifampin dose versus the standard dose in pulmonary tuberculosis patients. Antimicrobial agents and chemotherapy 2007;51:2546-2551.

13. Rifampin. Tuberculosis 2008;88:151-154.

14. Knowles SR, Uetrecht J, Shear NH. Idiosyncratic drug reactions: The reactive metabolite syndromes. Lancet 2000;356:1587-1591.

15. Solera J, Rodriguez-Zapata M, Geijo P, Largo J, Paulino J, Saez L, Martinez-Alfaro E, Sanchez L, Sepulveda MA, Ruiz-Ribo MD. Doxycycline-rifampin versus doxycycline-streptomycin in treatment of human brucellosis due to brucella melitensis. The gecmei group. Grupo de estudio de castilla-la mancha de enfermedades infecciosas. Antimicrobial agents and chemotherapy 1995;39:2061-2067.

16. Kochar DK, Aseri S, Sharma BV, Bumb RA, Mehta RD, Purohit SK. The role of rifampicin in the management of cutaneous leishmaniasis. QJM : monthly journal of the Association of Physicians 2000;93:733-737.

17. Edelstein PH, Meyer RD. Legionnaires' disease. A review. Chest 1984;85:114-120.

18. Kissling M, Bergamini N. Rifampicin in free combination with other antimicrobial drugs in non-tb infections. Clinical data on 650 patients (a review). Chemotherapy 1981;27:368-402. 
19. Zimmerli W, Trampuz A, Ochsner PE. Prosthetic-joint infections. The New England journal of medicine 2004;351:1645-1654.

20. Poole G, Stradling P, Worlledge S. Potentially serious side effects of high-dose twice-weekly rifampicin. British medical journal 1971;3:343-347.

21. Boeree MJ, Diacon AH, Dawson R, Venter A, du Bois J, Narunsky K, Hoelscher M, Gillespie SH, Phillips PPJ, Aarnoutse RE. What is the "right" dose of rifampin? . 20th Conference on Retroviruses and Opportunistic Infections. Atlanta; 2013. p. 148LB.

22. Acocella G. Clinical pharmacokinetics of rifampicin. Clinical pharmacokinetics 1978;3:108127.

23. Sibille M, Patat A, Caplain H, Donazzolo Y. A safety grading scale to support dose escalation and define stopping rules for healthy subject first-entry-into-man studies: Some points to consider from the french club phase i working group. British journal of clinical pharmacology 2010;70:736-748.

24. Http://evs.Nci.Nih.Gov/ftp1/ctcae/ctcae $4.03 \quad 2010-06-14$ quickreference 5x7.Pdf.

25. Donald PR, Sirgel FA, Venter A, Parkin DP, Seifart HI, van de Wal BW, Maritz JS, Fourie PB. Early bactericidal activity of antituberculosis agents. Expert review of anti-infective therapy 2003;1:141-155.

26. Rustomjee R, Diacon AH, Allen J, Venter A, Reddy C, Patientia RF, Mthiyane TC, De Marez T, van Heeswijk R, Kerstens R, Koul A, De Beule K, Donald PR, McNeeley DF. Early bactericidal activity and pharmacokinetics of the diarylquinoline tmc207 in treatment of pulmonary tuberculosis. Antimicrobial agents and chemotherapy 2008;52:2831-2835.

27. Long JS. Regression models for categorical and limited dependent variables. Thousand Oaks, CA, USA: Sage Publications; 1997.

28. Kreis B, Pretet S, Birenbaum J, Guibout P, Hazeman JJ, Orin E, Perdrizet S, Weil J. Two threemonth treatment regimens for pulmonary tuberculosis. Bulletin of the International Union against Tuberculosis 1976;51:71-75. 
29. Pasipanodya JG, Mcllleron H, Burger A, Wash PA, Smith P, Gumbo T. Serum drug concentrations predictive of pulmonary tuberculosis outcomes. The Journal of infectious diseases 2013;208:1464-1473.

30. Srivastava S, Pasipanodya JG, Meek C, Leff R, Gumbo T. Multidrug-resistant tuberculosis not due to noncompliance but to between-patient pharmacokinetic variability. The Journal of infectious diseases 2011;204:1951-1959.

31. Pasipanodya JG, Srivastava S, Gumbo T. Meta-analysis of clinical studies supports the pharmacokinetic variability hypothesis for acquired drug resistance and failure of antituberculosis therapy. Clinical infectious diseases : an official publication of the Infectious Diseases Society of America 2012;55:169-177.

32. Dooley KE, Bliven-Sizemore EE, Weiner M, Lu Y, Nuermberger EL, Hubbard WC, Fuchs EJ, Melia MT, Burman WJ, Dorman SE. Safety and pharmacokinetics of escalating daily doses of the antituberculosis drug rifapentine in healthy volunteers. Clinical pharmacology and therapeutics 2012;91:881-888.

33. Ruslami R, Ganiem AR, Dian S, Apriani L, Achmad TH, van der Ven AJ, Borm G, Aarnoutse RE, van Crevel R. Intensified regimen containing rifampicin and moxifloxacin for tuberculous meningitis: An open-label, randomised controlled phase 2 trial. The Lancet infectious diseases 2013;13:27-35.

34. Jia L, Tomaszewski JE, Hanrahan C, Coward L, Noker P, Gorman G, Nikonenko B, Protopopova M. Pharmacodynamics and pharmacokinetics of sq109, a new diamine-based antitubercular drug. British journal of pharmacology 2005;144:80-87. 


\section{ABSTRACT}

Rationale: Rifampin at a dose of $10 \mathrm{mg} / \mathrm{kg}$ was introduced in 1971 based on pharmacokinetic, toxicity and cost considerations. Available data in mice and humans showed that an increase in dose may shorten the duration of tuberculosis treatment. Objectives: To evaluate the safety and tolerability, the pharmacokinetics and the extended early bactericidal activity of increasing doses of rifampin.

Methods: Patients with drug-susceptible tuberculosis were enrolled into a control group of 8 patients receiving the standard dose of $10 \mathrm{mg} / \mathrm{kg}$ rifampin, followed by consecutive experimental groups with 15 patients each receiving rifampin $20 \mathrm{mg} / \mathrm{kg}, 25 \mathrm{mg} / \mathrm{kg}, 30 \mathrm{mg} / \mathrm{kg}$ and $35 \mathrm{mg} / \mathrm{kg}$, respectively, for 14 days. In all patients isoniazid, pyrazinamide and ethambutol were added in standard doses for the second 7 days of treatment. Safety, pharmacokinetics of rifampin, and fall in bacterial load were assessed.

Measurements and Main Results: Grade 1 and 2 adverse events were equally distributed between the five dose groups; there were 5 grade 3 events of which 1 was a possibly related hepatotoxicity. Areas under the time-concentration curves and peak serum concentrations of rifampin showed a more than proportional increase with dose. The daily fall in bacterial load over 14 days was $0.176,0.168,0.167,0.265$, and $0.261 \log _{10} \mathrm{CFU} / \mathrm{ml}$ sputum in the 10 , $20,25,30$ and $35 \mathrm{mg} / \mathrm{kg}$ groups respectively.

Conclusions: Two weeks of rifampin up to $35 \mathrm{mg} / \mathrm{kg}$ was safe and well tolerated. There was a non-linear increase in exposure to rifampin without an apparent ceiling effect and a greater estimated fall in bacterial load in the higher dosing groups. (ClinicalTrials.gov number NCT01392911) 
Word count abstract: 258

\section{INTRODUCTION}

Rifampin is one of the pivotal drugs for the treatment of tuberculosis. The US Food and Drug Administration approved rifampin in 1971 and several trials showed that rifampin containing-regimens were very effective: in combination with pyrazinamide, it became possible to shorten the duration of treatment to six months.(1) Six-month rifampincontaining regimens are now the standard of care and recommended by national and international bodies including the American Thoracic Society and the World Health Organization. Virtually all of the studies that underpin these recommendations used a dose of $10 \mathrm{mg}$ rifampin $/ \mathrm{kg}$.(2) A dose finding study with an assessment of the maximum tolerated dose(3) was never performed. The recommended dose was chosen on the basis that it was effective at the lowest cost and limited by fear of adverse effects.

There is an accumulating body of evidence that suggest that higher doses of rifampin may be more effective and lead to significant shortening of the duration of tuberculosis treatment. In vitro experiments in a pharmacokinetic-pharmacodynamic model of tuberculosis showed that higher doses of rifampin kill the bacteria more rapidly and prevent the emergence of resistance to rifampin(4). Mouse experiments showed increased killing of bacteria and enhanced sterilizing activity with higher doses, resulting in a significant shortening of treatment duration.(5-7) Additionally, an estimation of maximum tolerated dose in mice was shown to be $160 \mathrm{mg}$ rifampin/ $\mathrm{kg}(7)$. Studies of monotherapy with rifampin in tuberculosis patients demonstrated that a moderate increase in the dose of rifampin leads to a steeper 
fall of bacterial load over time.(8-10) A systematic review of 14 randomized controlled trials that evaluated higher doses up to $20 \mathrm{mg}$ rifampin/kg in humans, most of them performed before 1980, suggests that higher doses of rifampin result in improved culture conversion rates.(11) A trial in pulmonary tuberculosis patients in Indonesia comparing $450 \mathrm{mg}$ rifampin $(10 \mathrm{mg} / \mathrm{kg})$ to $600 \mathrm{mg} / \mathrm{kg}(13 \mathrm{mg} / \mathrm{kg})$ rifampin showed a nonlinear, more than proportional increase of pharmacokinetic exposure.(12)

The adverse effects of rifampin at the standard dose are well known, because of years of worldwide use since its introduction.(13) Yet, the relationship between dose and adverse events is not well established and may be either toxic with a clear relation or idiosyncratic without such a relation.(14) There have been trials and case series that used higher doses of rifampin in tuberculosis and other infections such as brucellosis, leishmaniasis, Legionnaires' disease, and bone and joint infections $(2,15-19)$ without severe adverse effects. Some events, such as the flu like syndrome are likely related to intermittent dosing.(20)

If increasing rifampin may be more effective and could shorten therapy there is an urgent need to know the optimum dose. We performed a study in tuberculosis patients, therefore, to establish the maximum tolerated dose, to assess the incidence and severity of adverse events, to describe the pharmacokinetics and to measure the bactericidal effect of higher doses of rifampin.

Some of the results of these studies have been previously reported in the form of an abstract. (21) 


\section{METHODS}

\section{Patients}

Adults (18 to 65 ) with newly diagnosed, previously untreated, sputum smear-positive uncomplicated pulmonary tuberculosis and with no medical contraindications (see Table E1 in the online data supplement) were included in the study. For HIV positive subjects a CD4 count of $\geq 350$ cells was an additional inclusion criterion. Patients were hospitalized in one of two study sites in Cape Town, South Africa.

\section{Study design}

We performed an open-label phase II multiple dose ranging study to evaluate safety, tolerability, pharmacokinetics and extended early bactericidal activity of increasing doses of rifampin. All patients received a specified dose of rifampin for 14 days, given in monotherapy for the first 7 days and supplemented with standard doses of isoniazid 5 $\mathrm{mg} / \mathrm{kg}$, pyrazinamide $25-30 \mathrm{mg} / \mathrm{kg}$ and ethambutol $15-20 \mathrm{mg} / \mathrm{kg}$ for the last 7 days. The patients then continued standard tuberculosis treatment (Figure 1) and had visits at 3 and 12 weeks for clinical assessment and sputum culture for susceptibility testing.

The first 8 patients were enrolled in a control cohort receiving $10 \mathrm{mg}$ rifampin $/ \mathrm{kg}$. Subsequently, patients were enrolled in consecutive intervention cohorts of 15 patients each. The first cohort received rifampin at a dose of $20 \mathrm{mg} / \mathrm{kg}$. The second cohort received $25 \mathrm{mg}$ rifampin/ $\mathrm{kg}$, the third $30 \mathrm{mg}$ rifampin $/ \mathrm{kg}$ and the last cohort received $35 \mathrm{mg}$ 
rifampin/kg. Of note, the consecutive dose increases for rifampin were relatively small, considering the non-linear pharmacokinetics of rifampin, which means that an increase in dose may result in an unpredictable, disproportionally larger increase in exposure.(22)

After completion of follow-up by all subjects in each cohort, the Trial Steering Committee, reviewed all of the safety data for the cohort before the first patient in the next cohort was enrolled. Two subjects experiencing a grade 3 adverse event assessed as probably or definitely related to administration of high dose rifampin, or one subject experiencing a grade 4 or 5 adverse event assessed as definitely related to rifampin, would lead to a meeting of the Trial Steering Committee to discuss the continuation or termination of the study.(23)

The study protocol was approved by local ethical review boards and by the Medical Control Council of South Africa and was conducted according to Good Clinical Practice standards. All patients provided written informed consent before enrolment in the study.

The innovative design of this study differs from a classical "early bactericidal activity" study intended for comparison.

\section{Drug management}

During the 7 days of rifampin monotherapy, patients received rifampin administered as capsules Rifadin ${ }^{\circledR}$ (150 mg, 300 mg and /or 600 mg) from Sanofi-Aventis. Combination therapy of rifampin, isoniazid, pyrazinamide and ethambutol during the subsequent 7 days was administered in the form of the fixed dose combination (FDC) Rifafour ${ }^{\circledR}$ e-275 from Sanofi-Aventis, containing $150 \mathrm{mg}$ rifampin, $75 \mathrm{mg}$ isoniazid, $400 \mathrm{mg}$ pyrazinamide and $275 \mathrm{mg}$ ethambutol per tablet. The subjects in the control group received only standard 
Rifafour $^{\circledR}$ e-275 treatment. The subjects in the other dosing groups received additional Rifadin ${ }^{\circledast}$ to reach the same pre-defined rifampin dose as administered in the monotherapy period. The exact amount of Rifafour ${ }^{\circledR} \mathrm{e}-275$ tablets and Rifadin ${ }^{\circledR}$ capsules was dependent on the dosing group of the patient and the patient's weight before start of the study. Daily treatment bottles for all 14 days were prepared in advance and checked by pharmacists or site staff members who were licensed for dispensing.

\section{Safety and tolerability}

The primary objective of this study was to assess the maximum tolerated dose, which is defined as the dose below that producing unacceptable but reversible toxicity. Tolerability is an aspect of safety and used to indicate how well a patient is able to endure treatment such that adverse events do not result in the discontinuation of treatment(3).

Symptoms assessments, physical examination, including vital signs, were performed on a daily base. Haematological, renal and liver function tests, glucose, uric acid and urinalysis and electrocardiography were scheduled at baseline and days 1, 3, 6, 10, 14 and 21 with appropriately narrow window periods. Adverse events were graded according to the US National Institute of Health Common Terminology Criteria for Adverse Events 4.0.(24) Patients with serious adverse events were followed up until resolution of the event. Events were assessed as unrelated, possibly or definitely related by site investigators (see Table E2 in the online data supplement).

\section{Pharmacokinetics}

Blood samples were taken on day 7 and day 14 with a standardized meal for a full pharmacokinetics curve. Total (protein-bound plus unbound) plasma concentrations of 
rifampin were measured at the Department of Pharmacy of the Radboud University Medical center, Nijmegen, the Netherlands, using a validated Ultra Performance Liquid Chromatography method with ultraviolet detection, derived from a previously described assay.(12) Noncompartmental pharmacokinetic analysis was performed with Winnonlin version 5.3 (Pharsight Corp., Mountain View, California US) to yield pharmacokinetic parameters, including the area under the plasma concentration-time curve $\left(A \cup C_{0-24 h}\right.$ or total exposure) and highest observed plasma concentration $\left(C_{\max }\right)$, as described before.(12)

\section{Antimycobacterial activity}

Spot sputum samples were collected before enrolment, at day 19 and after 12 weeks. The samples were prepared for direct microscopy, stained with the auramine $O$ method and presence of acid fast bacilli was scored using the IUATLD/WHO grading. Pooled overnight (16 hours) samples were collected at baseline, daily to day 7, days 9 and 14. Each sample was diluted and cultured in quadruplicate on selective Middlebrook 7H11 agar plates. Counts of colony forming units (CFU) were done after a minimum of 21 days of incubation to assess the fall of CFU over time. $(25,26)$ In addition, the samples were processed for culture in liquid broth medium according to the mycobacterial growth indicator tube (Bactec MGIT960) system. Time-to-positivity (TTP) was determined for each sample to assess the change in TTP over time. The remainder of the baseline samples were processed to determine susceptibility tests and an Accuprobe identification (Gen-Probe ${ }^{\circledR}$ ) test was carried out to confirm presence of M. tuberculosis complex. All microbiological testing was performed in the Department of Medical Biochemistry, Faculty of Medicine and Health Sciences, Stellenbosch University, Cape Town, South Africa. 


\section{Statistical analysis}

This was a descriptive study with no inferential statistics or hypothesis testing. The planned sample size of 15 patients in each group is in keeping with other trials of this type and accounts for the site conservative estimate of 3 dropouts per group.(3) Safety was expressed as incidence of adverse events by severity and relatedness. The AUCO-24h and Cmax of rifampin at days 7 and 14 were presented as geometric means by study group. The distribution of TTP on MGIT was positively skewed with log-transformed TTP more closely following a symmetric normal distribution. Mixed effects models with visit day as a discrete random effect were used to estimate the mean logCFU and logTTP in each treatment arm at each visit to describe the data. LogCFU of 1 or TTP of 42 days was used for negative cultures in this analysis. We found an unexpectedly high number of negative cultures for the short treatment duration. These data points would usually be excluded with standard regression methods due to the quantitative measure of logCFU or TTP being below or above the limit of detection. In order to include these censored observations, Tobit regression(27) was used to estimate the 14-day early bactericidal activity, accounting for negatives cultures using a lower limit of detection censoring for logCFU of 1 and an upper limit for TTP of 42 days. Separate models were fitted for each patient with parameter estimates summarised by treatment group using a random effects model accounting for within- and between- patient variability. Linear regression was used to explore the relationship between 14-day early bactericidal activity and each of actual dose received in $\mathrm{mg}$, actual dose received in $\mathrm{mg} / \mathrm{kg}$ 
and exposures achieved $\left(\mathrm{AUC}_{0-24}\right.$ and $\left.\mathrm{C}_{\max }\right)$ comparing models using the proportion of variation explained, $\mathrm{R}^{2}$.

\section{RESULTS}

\section{Patients}

A total of 68 culture positive pulmonary tuberculosis patients were recruited between June 2011 and April 2012 with the last patient completing follow-up in August 2012. Patient characteristics are shown in Table 1.

\section{Safety/tolerability}

The stopping criteria were not met and the Trial Steering Committee recommended that the trial continued after data safety review at the end of each cohort. None of the patients discontinued or were withdrawn from the study. There were a total of 163 adverse events: 128 grade 1, 30 grade 2 , and 5 grade 3 adverse events. No grade 4 and 5 adverse events occurred. 53 adverse events were unrelated to rifampin, 102 were "possibly" related and 8 were assessed to be "definitely" related to rifampin (Table 2).

The most common adverse events related to monotherapy with rifampin were abdominal pain, vomiting, headache, and pruritus. The most common adverse events related to the combination treatment with rifampin, isoniazid, pyrazinamide and ethambutol were vomiting, headache, hyperuricaemia, pain in the extremities and pruritus. These adverse events occurred in all groups and were not attributable to a specific dose group. 


\section{Pharmacokinetics}

The average $\mathrm{AUC}_{0-24}$ and $\mathrm{C}_{\max }$ values of rifampin at day 14 are presented in Table 3. Upon doubling the dose of rifampin from $10 \mathrm{mg} / \mathrm{kg}$ to $20 \mathrm{mg} / \mathrm{kg}$, the geometric mean $\mathrm{AUC}_{0-24}$ of rifampin increased more than four-fold, which reflects a more than dose-proportional increase of exposure with the dose. No ceiling in rifampin $A U C_{0-24}$ or flattening of the relationship between dose administered and $\mathrm{AUC}_{0-24}$ achieved was observed. Strong increases in average rifampin Cmax with the dose were also observed (Table 3). Of note, large interindividual variability in $\mathrm{AUC}_{0-24 \mathrm{~h}}$ and $\mathrm{C}_{\max }$ was observed (Table 3 and Figure 2), yet the minimum exposure recorded in each group (either in terms of $A \cup C_{0-24 h}$ or $C_{\text {max }}$ ) increased with the dose administered.

\section{Antimycobacterial activity}

One patient in the $20 \mathrm{mg} / \mathrm{kg}$ group was negative on solid media at all but one sample and these data were therefore removed from all analyses. The fall in bacterial load in sputum over time expressed as CFU and TTP is summarized in Figure 3. The highest doses of 30 and $35 \mathrm{mg} / \mathrm{kg}$ show highest 14-day early bactericidal activity on both CFU and TTP (Figure 4). There was no clear biphasic curve from days 7-14 after which the other drugs, including isoniazid were added. At 14 days, 8 of 14 patients in the $35 \mathrm{mg} / \mathrm{kg}$ group were culture negative on solid media as compared to 3 of 8 in the control group, 5 of 14 in the $20 \mathrm{mg} / \mathrm{kg}$ group, 0 of 15 in the $25 \mathrm{mg} / \mathrm{kg}$ and 2 of 15 in the $30 \mathrm{mg} / \mathrm{kg}$ group.

$\mathrm{AUC}_{0-24 \mathrm{~h}}$ at day 14 was a better predictor of 14-day early bactericidal activity on CFU $\left(R^{2}=0.12\right)$ than dose in $\mathrm{mg} / \mathrm{kg}$ received $\left(\mathrm{R}^{2}=0.06\right)$ or the dose in $\mathrm{mg}\left(\mathrm{R}^{2}=0.05\right)$, although the proportion of explained variance was low. $\mathrm{AUC}_{0-24 \mathrm{~h}}$ was a marginally better predictor of $14-$ 
day early bactericidal activity on TTP $\left(R^{2}=0.19\right)$ than dose in $\mathrm{mg} / \mathrm{kg}$ received $\left(R^{2}=0.18\right)$ or the dose in $\mathrm{mg}\left(\mathrm{R}^{2}=0.12\right)$.

\section{DISCUSSION}

This study shows that doses of rifampin that are considerably higher than the standard dose are safe and well tolerated. As accumulating evidence indicates that higher doses of and increased exposures to rifampin are more efficacious in tuberculosis treatment, $(5-7,10,11$, $28,29)$ we believe that this finding may change the landscape of treatment for drug susceptible tuberculosis and may permit shortening of the duration of treatment, as rifampin is a very strong sterilizer. In addition, there is evidence that an important driver behind the emergence of multidrug-resistant tuberculosis is low exposures of especially rifampin caused by inter-individual pharmacokinetic variability. $(4,30,31)$ The current standard dose of rifampin used in the last 40 years is probably considerably too low in many patients.

The primary objective of this study was to estimate the maximum tolerated dose of rifampin and it was significant that dose-limiting toxicities were not found at the highest administered dose of $35 \mathrm{mg} / \mathrm{kg}$ daily. Higher doses than $35 \mathrm{mg} / \mathrm{kg}$ were not planned before the study, as very high exposures to rifampin were anticipated at this dose and the study did not have unrestricted funding.

The pharmacokinetic behaviour of rifampin over the range of increasing doses was more than dose-proportional, "super-proportional". The average $\mathrm{AUC}_{0-24}$ at $35 \mathrm{mg} / \mathrm{kg}$ was almost 
10 -fold higher than the average exposure at $10 \mathrm{mg} / \mathrm{kg}$ rifampin. This phenomenon was previously described in other studies for lower doses. $(12,22)$ We did not observe a ceiling effect as was reported in the pharmacokinetics of one of the other promising rifamycins, rifapentine.(32) Importantly, apart from average exposures, the lowest observed $\mathrm{AUC}_{0-24 \mathrm{~h}}$ and $C_{\max }$ values also increased, with almost every dose step (Table 3 and Figure 2). This is what we aimed for, as it is probably the lowest exposures that cause treatment failures and relapses thereby preventing treatment shortening. In addition, these low exposures may favor the emergence of resistance. $(4,30,31)$ We showed, however, that there was a large inter-individual variation in pharmacokinetics (Figure 2). This is a warning for further studies of high doses of rifampin, as individual exposures may be much higher than our observed means. This may have a beneficial effect in terms of efficacy, but may also cause an increased risk of toxicity.

There was a greater estimated fall in bacterial load in the higher dosing groups dose as measured by a larger fall in CFUs over time and by a more rapid increase in TTP over time. This study was not powered for efficacy and these differences were not statistically significant. Although this result is encouraging, the finding may not necessarily indicate increased efficacy in terms of treatment failure and relapse, the definitive patient-relevant outcomes and phase III endpoints. In mouse models, however, there is evidence that higher doses of rifampin sterilize and cure the mice in a shorter period of time.(5-7) Additionally, in a recent clinical trial in Indonesian tuberculous meningitis patients higher doses of rifampin (around $13 \mathrm{mg} / \mathrm{kg}$ intravenously as compared to around $10 \mathrm{mg} / \mathrm{kg}$ orally) led to a decreased 6 months mortality of roughly $50 \% .(33)$ 
By design, small numbers of patients selected on the basis of very strict criteria were treated for only a short period of time with higher doses of rifampin. Therefore, our findings need to be confirmed in longer phase II studies with less narrow inclusion criteria and adequate patients numbers before being tested in a phase III study. Currently, two studies have started with this objective. The first randomized controlled trial has recently finished enrolment (ClinicalTrials.gov NCT00760149) and compared a control group with the standard tuberculosis regimen with two groups of $15 \mathrm{mg}$ rifampin/ $/ \mathrm{kg}$ and $20 \mathrm{mg}$ rifampin/kg combined with isoniazid, pyrazinamide and ethambutol for two months in groups of 50 patients each. The second study with a multi arm multi stage (MAMS) design performed within the PanACEA consortium (ClinicalTrials.gov NCT01785186) compares a standard control group with a group on $20 \mathrm{mg}$ rifampin/ $\mathrm{kg}$ combined with moxifloxacin, isoniazid and pyrazinamide, a group with $20 \mathrm{mg}$ rifampin/kg combined with the new compound SQ109(34) and isoniazid and pyrazinamide, and a group with $35 \mathrm{mg}$ rifampin/ $\mathrm{kg}$ combined with isoniazid, pyrazinamide and ethambutol for three months. A further two month study is evaluating $15 \mathrm{mg}$ rifampin/kg and $20 \mathrm{mg}$ rifampin/kg in Peru (ClinicalTrials.gov NCT01408914). Depending on the results of these trials, we are planning to extend the study in this paper and increase the dose until the actual maximum tolerated dose is reached. In conclusion, higher doses of rifampin up to $35 \mathrm{mg} / \mathrm{kg}$ were safe and well tolerated for two weeks. The higher doses of rifampin achieved up to 10-fold higher average exposures in plasma, due to nonlinear "super-proportional" pharmacokinetic behaviour. The greater estimated fall in bacterial load measured by CFUs and TTP suggests an increased efficacy in the higher dosing groups supporting the idea that this critical drug is being administered at too low a dose. With the results of phase IIB studies currently underway that further 
examine these higher dose, we should look forward to a pivotal phase III trial to definitely answer the question what the right dose of rifampin is.

\section{Acknowledgments}

We thank Prof. Peter R. Donald from the Stellenbosch University, Tygerberg, South Africa and Prof. Paul A. Willcox, University of Cape Town, Cape Town, South Africa for their role in the Trial Steering Committee. 


\begin{tabular}{|c|c|c|c|c|}
\hline All & $10 \mathrm{mg}$ & $20 \mathrm{mg}$ & $25 \mathrm{mg}$ & $30 \mathrm{mg}$ \\
\hline Subjects & RIF/kg & RIF/kg & RIF/kg & RIF/kg \\
\hline
\end{tabular}

$\mathrm{N}$

68

8

15

15

15

15

Age (yr)

\begin{tabular}{lrrrrrr} 
Median & 30.5 & 27.5 & 27.0 & 25.0 & 40.0 & 37.0 \\
Range & $18-59$ & $19-49$ & $18-46$ & $19-46$ & $19-59$ & $21-59$ \\
\hline
\end{tabular}

Weight (kg)

\begin{tabular}{|c|c|c|c|c|c|c|}
\hline Median & 53.6 & 56.9 & 52.5 & 52.8 & 54.0 & 57.0 \\
\hline Range & $40.2-84.2$ & $46.8-64.9$ & $41.8-62.7$ & $40.2-67.9$ & $45.7-84.2$ & $40.5-74.0$ \\
\hline
\end{tabular}

Body-Mass Index (kg/m^2)

\begin{tabular}{lcccccr}
\hline Median & 19.4 & 20.5 & 18.4 & 19.3 & 20.9 & 19.5 \\
Range & $14.7-30.9$ & $15.8-26.3$ & $16.8-26.2$ & $15.1-25.2$ & $16.4-30.9$ & $14.7-25.2$ \\
\hline
\end{tabular}

Male sex no.

$48(71)$

$6(75)$

$11(73)$

$10(67)$

$11(73)$

$10(67)$

Race -no (\%)

\begin{tabular}{|c|c|c|c|c|c|c|}
\hline Black & $28(41)$ & $3(38)$ & 7 (47) & $4(27)$ & $9(60)$ & $5(33)$ \\
\hline Coloured & 40 (59) & $5(63)$ & $8(53)$ & $11(73)$ & $6(40)$ & 10 (67) \\
\hline
\end{tabular}

HIV-positive (\%) 1(1,5)

$1(13)$

Baseline log10CFU/mI median

\begin{tabular}{|c|c|c|c|c|c|}
\hline (range) & $\begin{array}{c}4.88 \\
(2.15-5.85)\end{array}$ & $\begin{array}{c}4.00 \\
\text { (negative*-5.82) }\end{array}$ & $\begin{array}{l}5.39 \\
(3.70-6.38)\end{array}$ & $\begin{array}{c}4.58 \\
(2.68-6.25)\end{array}$ & $\begin{array}{c}4.39 \\
(2.86-5.82)\end{array}$ \\
\hline Baseline TTP / days median & 6.04 & 7.35 & 6.75 & 8.08 & 8.22 \\
\hline (range) & $(4.15-12.17)$ & $(4.44-13.33)$ & $(5.00-10.69)$ & $(4.81-13.46)$ & $(4.75-20.04)$ \\
\hline
\end{tabular}

Table1. Demographic and baseline characteristics at inclusion. * One patient on $20 \mathrm{mg} / \mathrm{kg}$ group was negative on solid media at all but one visit and their data was therefore removed from all analyses. 


\begin{tabular}{|c|c|c|c|c|c|c|c|}
\hline Group & Total & \multicolumn{2}{|c|}{ Grade 1 } & \multicolumn{2}{c|}{ Grade 2 } & \multicolumn{2}{c|}{ Grade 3 * } \\
\hline Relatedness & & $\begin{array}{c}\text { Possibly } \\
\text { related }\end{array}$ & Related & $\begin{array}{c}\text { Possibly } \\
\text { related }\end{array}$ & Related & $\begin{array}{c}\text { Possibly } \\
\text { related }\end{array}$ & Related \\
\hline $\begin{array}{c}10 \mathrm{mg} / \mathrm{kg} \\
\text { (control) }\end{array}$ & 7 & 0 & 0 & 0 & 0 & 0 & 0 \\
\hline $\begin{array}{c}20 \mathrm{mg} / \mathrm{kg} \\
\mathrm{RIF}\end{array}$ & 39 & 21 & 1 & 4 & 0 & 2 & 0 \\
\hline $\begin{array}{c}25 \mathrm{mg} / \mathrm{kg} \\
\mathrm{RIF}\end{array}$ & 24 & 11 & 2 & 2 & 0 & 0 & 0 \\
\hline $\begin{array}{c}30 \mathrm{mg} / \mathrm{kg} \\
\mathrm{RIF}\end{array}$ & 39 & 21 & 3 & 4 & 0 & 1 & 0 \\
\hline $\begin{array}{c}35 \mathrm{mg} / \mathrm{kg} \\
\text { RIF }\end{array}$ & 54 & 27 & 2 & 9 & 0 & 0 & 0 \\
\hline \begin{tabular}{c} 
Total \\
\hline
\end{tabular} & 163 & 80 & 8 & 19 & 0 & 3 & 0 \\
\hline
\end{tabular}

Table 2. Possibly related and definitely related adverse events per grade and per dose group *Among the grade 3 events there was a case of transient hyperkalemia of $6.1 \mathrm{mmol} / \mathrm{L}$ in the $20 \mathrm{mg} / \mathrm{kg} \mathrm{RIF}$ group that reoccurred in the same patient in week 3 (counted as two events). Potassium values normalized with no specific measures and no ECG changes were recorded. In the $30 \mathrm{mg} / \mathrm{kg}$ RIF group there was one grade 3 unrelated pleural effusion and a possibly related elevation of transaminase more than five times the upper limit of normal, which normalized spontaneously after repeat measurements. No grade 4 or grade 5 events were observed. 


\begin{tabular}{|l|l|l|}
\hline Group & $\mathrm{AUC}_{0-24 \mathrm{~h}}\left(\mathrm{~h}^{*} \mathrm{mg} / \mathrm{L}\right){ }^{*}$ & $\mathrm{C}_{\max }(\mathrm{mg} / \mathrm{L}) \#$ \\
\hline $10 \mathrm{mg} / \mathrm{kg}$ (control) & $26.3(21.3-40.9)$ & $7.4(6.1-9.9)$ \\
\hline $20 \mathrm{mg} / \mathrm{kg}$ & $113(77.5-162)$ & $21.6(16.0-31.9)$ \\
\hline $25 \mathrm{mg} / \mathrm{kg}$ & $135(91.5-228)$ & $25.1(16.3-34.6)$ \\
\hline $30 \mathrm{mg} / \mathrm{kg}$ & $190(84.7-436)$ & $33.1(17.6-55.8)$ \\
\hline $35 \mathrm{mg} / \mathrm{kg}$ & $235(166-321)$ & $35.2(28.6-44.2)$ \\
\hline
\end{tabular}

Table 3. Steady state PK of RIF (day 14) Geometric means and range *AUC ${ }_{0-24 h}$ : area under the time versus concentration curve up to $24 \mathrm{~h}$ post dose, $\mathrm{C}_{\max }$ : peak plasma concentration

\# Serial venous blood samples were taken just prior to and at $0.5,1,1.5,2,3,4,6,8,12,16$ and 24 hours after the investigational products were taken under direct supervision and with a standardized meal 


\section{Legends Figures}

Figure 1. Schematic overview of the study design

In each study group, monotherapy of rifampin for 7 days was administered using Rifadin ${ }^{\circledR}$ from Sanofi-Aventis in $150 \mathrm{mg}$ capsules, $300 \mathrm{mg}$ tablets or $600 \mathrm{mg}$ tablets. The combination of capsules and tablets for each patient was adjusted to achieve the correct dose by weight. In the subsequent period of 7 days, patients received a fixed dose combination tablet Rifafour ${ }^{\circledR}$ e-275, containing 150 mg rifampin, 75 mg isoniazid, 400 mg pyrazinamide and $275 \mathrm{mg}$ ethambutol, combined with additional rifampin (i.e. Rifadin ${ }^{\circledR}$ ) to reach the same pre-defined rifampin dose in $\mathrm{mg} / \mathrm{kg}$ as administered in the monotherapy period. Starting from day 15 the patients were administered Rifafour ${ }^{\circledR}$ e-275 only. All study medication was taken in the morning with a light breakfast and a glass of water. Administration of tuberculosis drugs was witnessed by site staff and a hand-andmouth procedure was performed to check for drug intake at every occasion.

Figure 2. Distribution of exposure to rifampin $\left(A \cup C_{0-24 h}\right)$ at day 14 in the various rifampin dosing groups. The reference line mimics a linear relationship.

Figure 3. Fitted estimates of differences from mean baseline $\log _{10} \mathrm{CFU}$ (upper panel) and $\log _{10} \mathrm{TTP} / \mathrm{ml}$ (lower panel) by visit and treatment arm

Figure 4. Early bactericidal activity of rifampin based on CFU (upper panel) and TTP (lower panel) per day 


\section{REFERENCES}

1. East African and Medical Research Councils. Controlled clinical trial of short-course (6-month) regimens of chemotherapy for treatment of pulmonary tuberculosis. Lancet 1972;1:1079-1085.

2. van Ingen J, Aarnoutse RE, Donald PR, Diacon AH, Dawson R, Plemper van Balen G, Gillespie $\mathrm{SH}$, Boeree MJ. Why do we use $600 \mathrm{mg}$ of rifampicin in tuberculosis treatment? Clinical infectious diseases : an official publication of the Infectious Diseases Society of America 2011;52:e194-199.

3. Modi M. Dose-finding studies in phase i and estimation of maximally tolerated dose. In: Ting N, editor. Dose finding in drug development: Springer New York; 2006. p. 30-48.

4. Gumbo T, Louie A, Deziel MR, Liu W, Parsons LM, Salfinger M, Drusano GL. Concentrationdependent mycobacterium tuberculosis killing and prevention of resistance by rifampin.

Antimicrobial agents and chemotherapy 2007;51:3781-3788.

5. Jayaram R, Gaonkar S, Kaur P, Suresh BL, Mahesh BN, Jayashree R, Nandi V, Bharat S, Shandil RK, Kantharaj E, Balasubramanian V. Pharmacokinetics-pharmacodynamics of rifampin in an aerosol infection model of tuberculosis. Antimicrobial agents and chemotherapy 2003;47:2118-2124.

6. Rosenthal IM, Tasneen R, Peloquin CA, Zhang M, Almeida D, Mdluli KE, Karakousis PC, Grosset JH, Nuermberger EL. Dose-ranging comparison of rifampin and rifapentine in two pathologically distinct murine models of tuberculosis. Antimicrobial agents and chemotherapy $2012 ; 56: 4331-4340$.

7. de Steenwinkel JE, Aarnoutse RE, de Knegt GJ, ten Kate MT, Teulen M, Verbrugh HA, Boeree MJ, van Soolingen D, Bakker-Woudenberg IA. Optimization of the rifampin dosage to improve the therapeutic efficacy in tuberculosis treatment using a murine model. American journal of respiratory and critical care medicine 2013;187:1127-1134.

8. Jindani A, Aber VR, Edwards EA, Mitchison DA. The early bactericidal activity of drugs in patients with pulmonary tuberculosis. The American review of respiratory disease 1980;121:939-949. 
9. Jindani A, Dore CJ, Mitchison DA. Bactericidal and sterilizing activities of antituberculosis drugs during the first 14 days. American journal of respiratory and critical care medicine 2003;167:1348-1354.

10. Diacon AH, Patientia RF, Venter A, van Helden PD, Smith PJ, Mcllleron H, Maritz JS, Donald PR. Early bactericidal activity of high-dose rifampin in patients with pulmonary tuberculosis evidenced by positive sputum smears. Antimicrobial agents and chemotherapy 2007;51:2994-2996. 11. Steingart KR, Jotblad S, Robsky K, Deck D, Hopewell PC, Huang D, Nahid P. Higher-dose rifampin for the treatment of pulmonary tuberculosis: A systematic review. The international journal of tuberculosis and lung disease : the official journal of the International Union against Tuberculosis and Lung Disease 2011;15:305-316.

12. Ruslami R, Nijland HM, Alisjahbana B, Parwati I, van Crevel R, Aarnoutse RE. Pharmacokinetics and tolerability of a higher rifampin dose versus the standard dose in pulmonary tuberculosis patients. Antimicrobial agents and chemotherapy 2007;51:2546-2551.

13. Rifampin. Tuberculosis 2008;88:151-154.

14. Knowles SR, Uetrecht J, Shear NH. Idiosyncratic drug reactions: The reactive metabolite syndromes. Lancet 2000;356:1587-1591.

15. Solera J, Rodriguez-Zapata M, Geijo P, Largo J, Paulino J, Saez L, Martinez-Alfaro E, Sanchez L, Sepulveda MA, Ruiz-Ribo MD. Doxycycline-rifampin versus doxycycline-streptomycin in treatment of human brucellosis due to brucella melitensis. The gecmei group. Grupo de estudio de castilla-la mancha de enfermedades infecciosas. Antimicrobial agents and chemotherapy 1995;39:2061-2067.

16. Kochar DK, Aseri S, Sharma BV, Bumb RA, Mehta RD, Purohit SK. The role of rifampicin in the management of cutaneous leishmaniasis. QJM : monthly journal of the Association of Physicians 2000;93:733-737.

17. Edelstein PH, Meyer RD. Legionnaires' disease. A review. Chest 1984;85:114-120.

18. Kissling M, Bergamini N. Rifampicin in free combination with other antimicrobial drugs in non-tb infections. Clinical data on 650 patients (a review). Chemotherapy 1981;27:368-402. 
19. Zimmerli W, Trampuz A, Ochsner PE. Prosthetic-joint infections. The New England journal of medicine 2004;351:1645-1654.

20. Poole G, Stradling P, Worlledge S. Potentially serious side effects of high-dose twice-weekly rifampicin. British medical journal 1971;3:343-347.

21. Boeree MJ, Diacon AH, Dawson R, Venter A, du Bois J, Narunsky K, Hoelscher M, Gillespie SH, Phillips PPJ, Aarnoutse RE. What is the "right" dose of rifampin? . 20th Conference on Retroviruses and Opportunistic Infections. Atlanta; 2013. p. 148LB.

22. Acocella G. Clinical pharmacokinetics of rifampicin. Clinical pharmacokinetics 1978;3:108127.

23. Sibille M, Patat A, Caplain H, Donazzolo Y. A safety grading scale to support dose escalation and define stopping rules for healthy subject first-entry-into-man studies: Some points to consider from the french club phase i working group. British journal of clinical pharmacology 2010;70:736-748.

24. Http://evs.Nci.Nih.Gov/ftp1/ctcae/ctcae $4.03 \quad 2010-06-14$ quickreference 5x7.Pdf.

25. Donald PR, Sirgel FA, Venter A, Parkin DP, Seifart HI, van de Wal BW, Maritz JS, Fourie PB. Early bactericidal activity of antituberculosis agents. Expert review of anti-infective therapy 2003;1:141-155.

26. Rustomjee R, Diacon AH, Allen J, Venter A, Reddy C, Patientia RF, Mthiyane TC, De Marez T, van Heeswijk R, Kerstens R, Koul A, De Beule K, Donald PR, McNeeley DF. Early bactericidal activity and pharmacokinetics of the diarylquinoline tmc207 in treatment of pulmonary tuberculosis. Antimicrobial agents and chemotherapy 2008;52:2831-2835.

27. Long JS. Regression models for categorical and limited dependent variables. Thousand Oaks, CA, USA: Sage Publications; 1997.

28. Kreis B, Pretet S, Birenbaum J, Guibout P, Hazeman JJ, Orin E, Perdrizet S, Weil J. Two threemonth treatment regimens for pulmonary tuberculosis. Bulletin of the International Union against Tuberculosis 1976;51:71-75. 
29. Pasipanodya JG, Mcllleron H, Burger A, Wash PA, Smith P, Gumbo T. Serum drug concentrations predictive of pulmonary tuberculosis outcomes. The Journal of infectious diseases 2013;208:1464-1473.

30. Srivastava S, Pasipanodya JG, Meek C, Leff R, Gumbo T. Multidrug-resistant tuberculosis not due to noncompliance but to between-patient pharmacokinetic variability. The Journal of infectious diseases 2011;204:1951-1959.

31. Pasipanodya JG, Srivastava S, Gumbo T. Meta-analysis of clinical studies supports the pharmacokinetic variability hypothesis for acquired drug resistance and failure of antituberculosis therapy. Clinical infectious diseases : an official publication of the Infectious Diseases Society of America 2012;55:169-177.

32. Dooley KE, Bliven-Sizemore EE, Weiner M, Lu Y, Nuermberger EL, Hubbard WC, Fuchs EJ, Melia MT, Burman WJ, Dorman SE. Safety and pharmacokinetics of escalating daily doses of the antituberculosis drug rifapentine in healthy volunteers. Clinical pharmacology and therapeutics 2012;91:881-888.

33. Ruslami R, Ganiem AR, Dian S, Apriani L, Achmad TH, van der Ven AJ, Borm G, Aarnoutse RE, van Crevel R. Intensified regimen containing rifampicin and moxifloxacin for tuberculous meningitis: An open-label, randomised controlled phase 2 trial. The Lancet infectious diseases 2013;13:27-35.

34. Jia L, Tomaszewski JE, Hanrahan C, Coward L, Noker P, Gorman G, Nikonenko B, Protopopova M. Pharmacodynamics and pharmacokinetics of sq109, a new diamine-based antitubercular drug. British journal of pharmacology 2005;144:80-87. 


\section{Page 50 of 59}

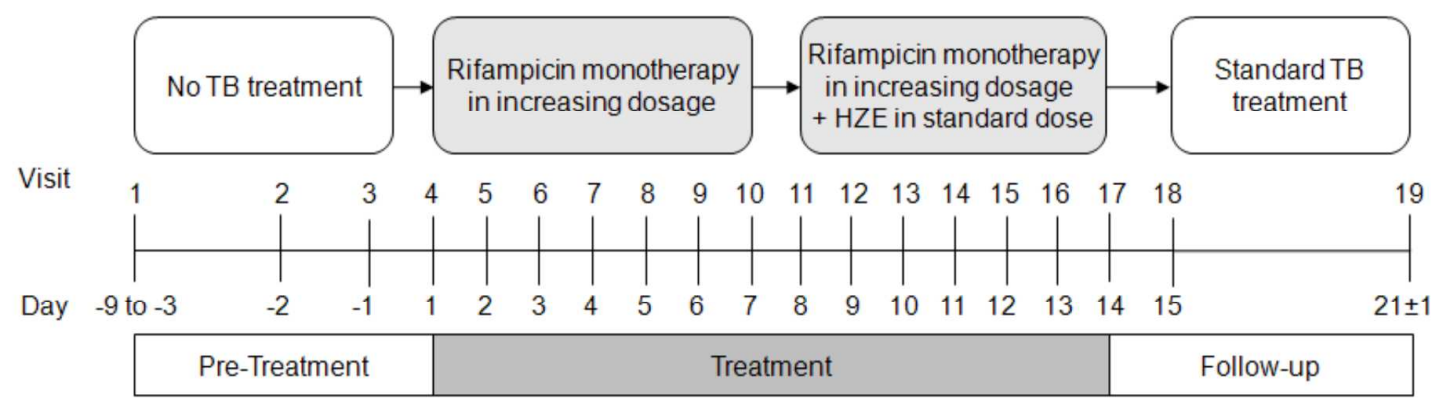




\section{Page 51 of 59}
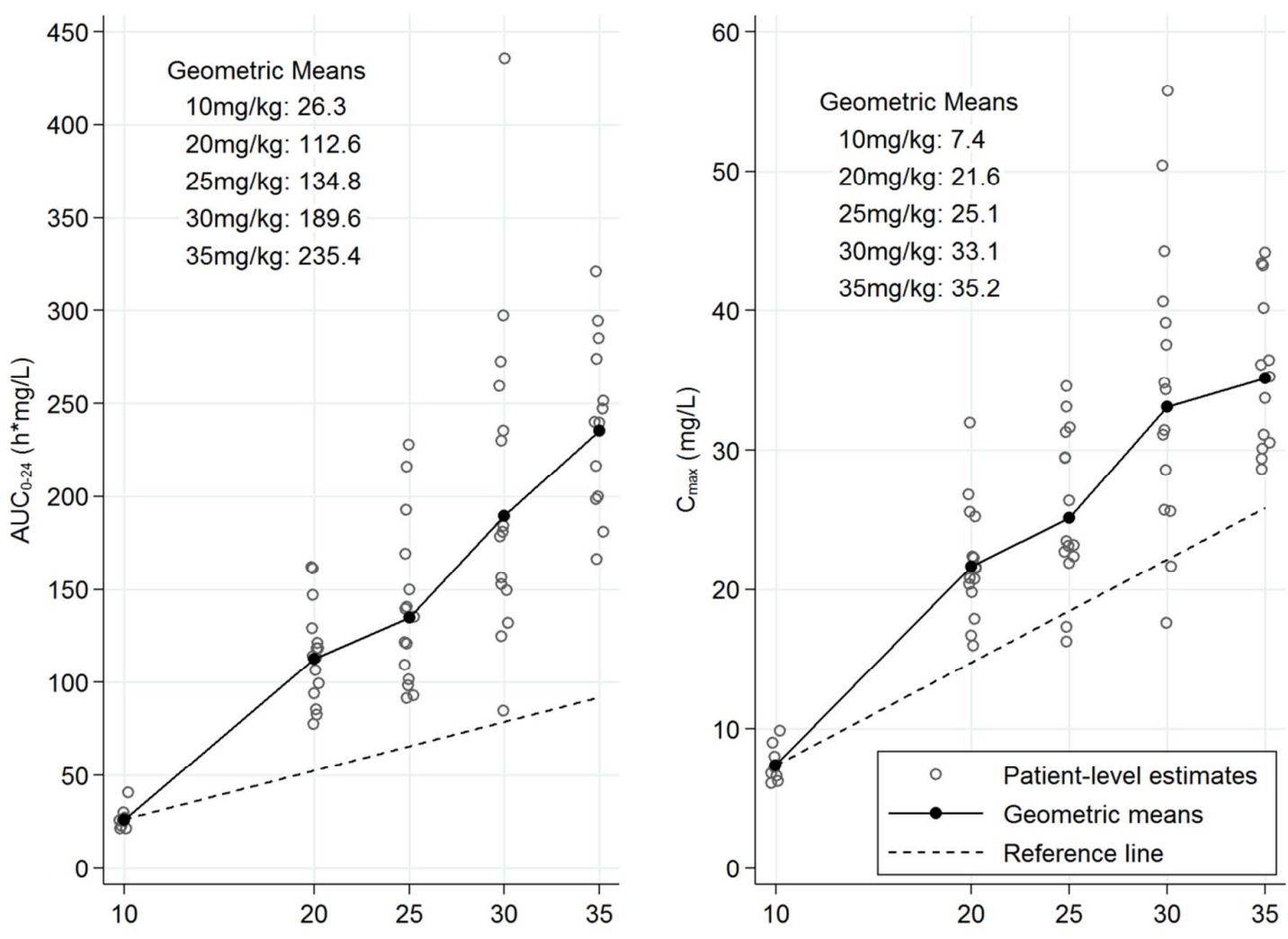
Page 52 of 59
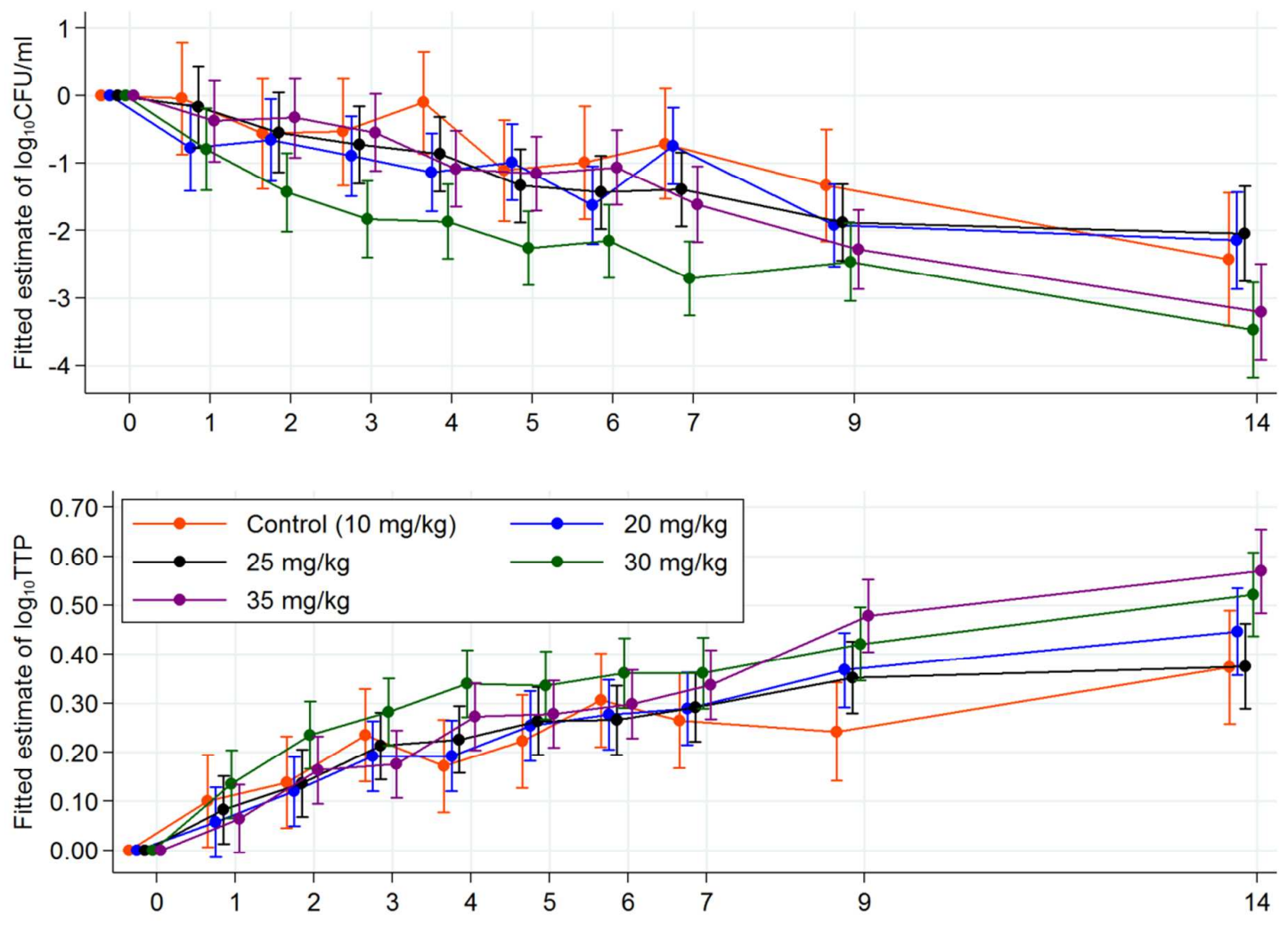


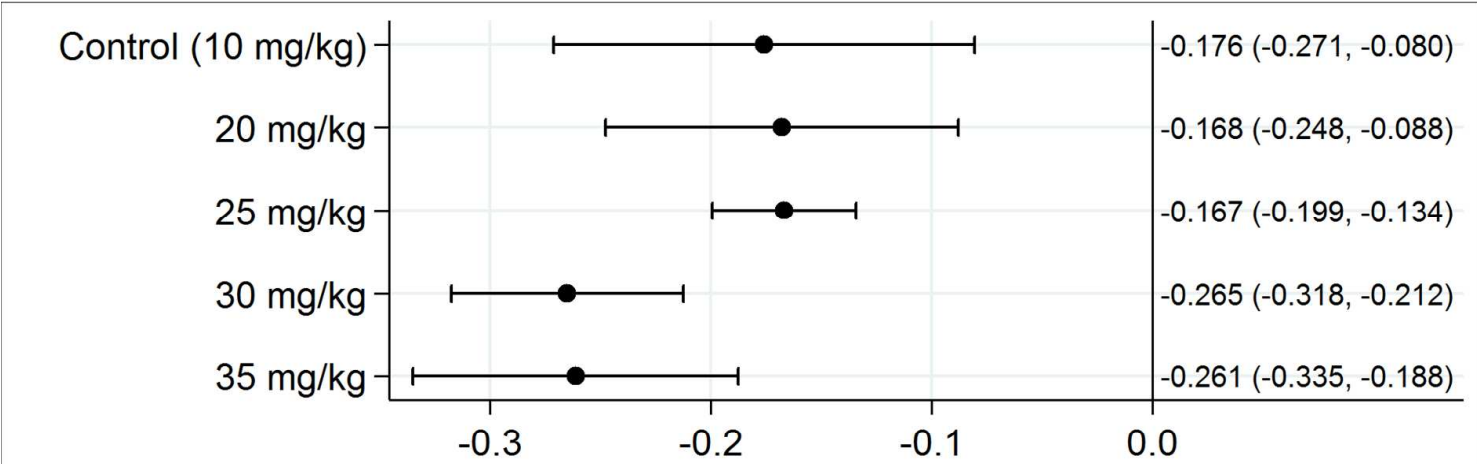

A. 14-day EBA with $95 \%$ confidence intervals, $\log _{10} \mathrm{CFU} / \mathrm{ml} /$ day

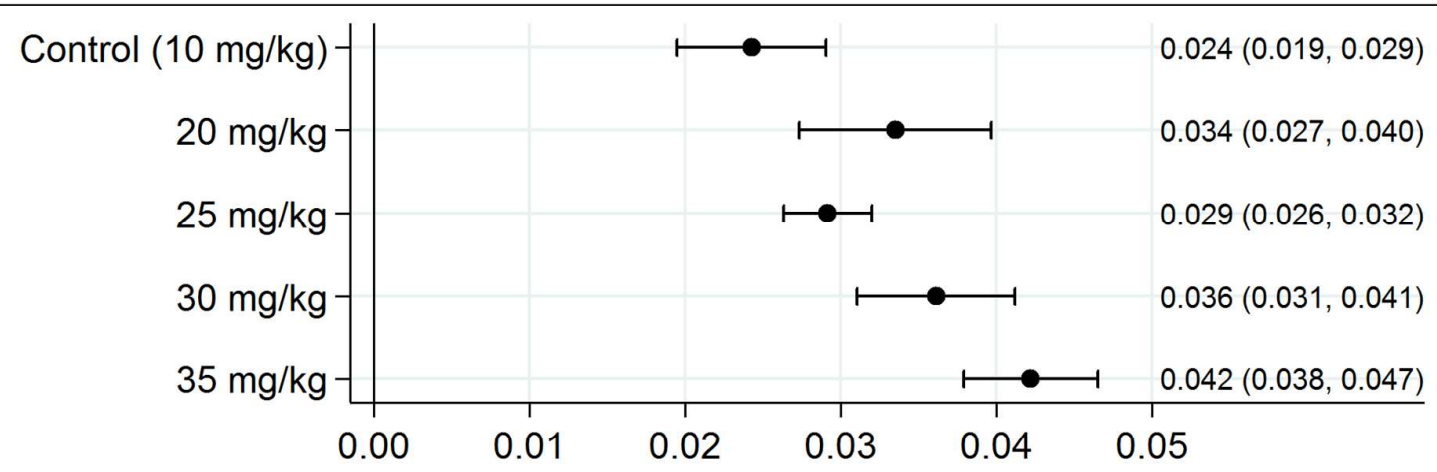

B. 14-day EBA with $95 \%$ confidence intervals, $\log _{10}$ TTP/day 
A dose escalating trial to optimize the dose of rifampin in the treatment of tuberculosis

Martin J. Boeree, Andreas H. Diacon, Rodney Dawson, Kim Narunsky, Jeannine du Bois, Amour Venter, Patrick P.J. Phillips, Stephen H. Gillespie, Timothy D. Mc Hugh, Michael Hoelscher, Norbert Heinrich, Sunita Rehal, Dick van Soolingen, Jakko van Ingen, Cecile MagisEscurra, David Burger, Georgette Plemper van Balen, Rob E. Aarnoutse

\section{Online Data Supplement}




\section{Table E1. Detailed inclusion and exclusion criteria}

Inclusion Criteria

Participants are required to meet all of the following inclusion criteria in order to be randomized:

1. Provide written, informed consent prior to all trial-related procedures including HIV testing.

2. Male or female, aged between 18 and 64 years inclusive.

3. Body weight (in light clothing and with no shoes) between 40 and $90 \mathrm{~kg}$, inclusive.

4. Newly diagnosed, previously untreated, uncomplicated, sputum smear-positive, pulmonary tuberculosis.

5. A chest X-ray picture which in the opinion of the Investigator is compatible with tuberculosis.

6. Sputum positive on direct microscopy for acid-fast bacilli (at least $1+$ on the IUATLD/WHO scale (Appendix 3)).

7. Ability to produce an adequate volume of sputum as estimated from a spot assessment (estimated $10 \mathrm{ml}$ or more overnight production).

8. Female participants of childbearing potential must have a negative serum pregnancy test and agree to use a highly effective method of birth control (i.e. two of the following precautions: tubal ligation, vaginal diaphragm, intrauterine device, condom or sponge with spermicide, oral contraceptives, contraceptive implant, combined hormonal patch, combined injectable contraceptive or depot-medroxyprogesterone acetate, partner(s) has had a vasectomy) throughout the participation in the trial and for 1 week after last dose, unless she and her partner(s) are sterile (that is, women who have had a bilateral 
oophorectomy and/or hysterectomy or have been postmenopausal for at least 12 consecutive months; men who have had bilateral orchidectomy).

9. Male participants must agree to use an adequate method of contraception (double barrier) throughout participation in the trial and for 12 weeks after last dose, unless he and his partner(s) are sterile (that is, women who have had a bilateral oophorectomy and/or hysterectomy or have been postmenopausal for at least 12 consecutive months; men who have had bilateral orchidectomy).

\section{Exclusion Criteria}

Participants will be excluded if they meet any of the following exclusion criteria prior to randomization:

1. Poor general condition where any delay in treatment cannot be tolerated per discretion of Investigator.

2. Rifampin-resistant and/or Isoniazid-resistant bacteria detected with a sputum specimen collected within the pre-treatment period and tested at the study laboratory.

3. Treatment received with any drug active against Mycobacterium tuberculosis within the 3 months prior to Visit 1 (isoniazid, ethambutol, amikacin, cycloserine, rifabutin, rifampin, streptomycin, kanamycin, para-aminosalicylic acid, rifapentine, pyrazinamide, thioacetazone, capreomycin, quinolones, thioamides, metronidazole).

4. A history of allergy to the IMP or related substances.

5. Clinically significant evidence of extrathoracic tuberculosis (miliary tuberculosis, abdominal tuberculosis, urogenital tuberculosis, osteoarthritic tuberculosis, tuberculous meningitis), as judged by the investigator.

6. A history of previous tuberculosis. 
7. Evidence of serious lung conditions other than tuberculosis or uncontrolled obstructive bronchial disease.

8. History of lens opacity or evidence of lens opacity on slit lamp ophthalmologic examination.

9. Any evidence of renal impairment, including but not limited to serum creatinine levels above the upper limit of the laboratory reference range, or hepatic impairment characterized by alanine aminotransferase (ALT) and/or aspartate transferase (AST) levels $>3$ times the upper limit of the laboratory reference range.

10. For males, any evidence or history of abnormality in the reproductive system, including but not limited to any one or more of the following: serum testosterone, luteinizing hormone (LH), and/or follicle-stimulating hormone (FSH) levels outside the laboratory reference range.

11. History and/or presence (or evidence) of neuropathy or epilepsy.

12. Clinically relevant changes in the ECG such as atrioventricular (AV) block, prolongation of the QRS complex over 120 milliseconds, or of either the QTcF or QTcB interval over 450 milliseconds on the screening ECG.

13. A history of or current clinically relevant cardiovascular disorder such as heart failure, coronary heart disease, hypertension, arrhythmia, tachyarrhythmia or status after myocardial infarction. Family history of sudden death of unknown or cardiac-related cause, or of prolonged QTc interval. Concomitant use of any drug known to prolong QTC interval (including amiodarone, bepridil chloroquine, chlorpromazine, cisapride, clarithromycin, disopyramide dofetilide, domperidone, droperidol, erythromycin, halofantrine, haloperidol, ibutilide, levomethadyl, mesoridazine, methadone, pentamidine, pimozide, procainamide, quinidine, sotalol, sparfloxacin, thioridazine). 
14. Diabetics using insulin.

15. Evidence of clinically significant metabolic, gastrointestinal, neurological, psychiatric or endocrine diseases, malignancy, or other abnormalities (other than the indication being studied).

16. Any diseases or conditions in which the use of the standard tuberculosis drugs or any of their components is contra-indicated, including but not limited to allergy to any tuberculosis drug, their component or to the IMP.

17. Any disease or conditions in which any of the medicinal products listed in the section pertaining to prohibited medication is used.

18. Known or suspected, current or history of within the past 2 years, alcohol or drug abuse, that is, in the opinion of the investigator, sufficient to compromise the safety or cooperation of the patient.

19. Administration of an IMP prior to Visit 1, within 5 half-lives for that IMP if known. If the half-life of the IMP is unknown within 1-month.

20. Pregnant, breast-feeding, or planning to conceive or father a child within twelve weeks of cessation of treatment for males and within one week of cessation of treatment for females.

21. Use of any drugs or substances within 30 days prior to dosing known to be strong inhibitors or inducers of cytochrome P450 enzymes (including xenobiotics, quinidine, tyramine, ketoconazole, testosterone, quinine, gestodene, metyrapone, phenelzine, doxorubicin, troleandomycin, cyclobenzaprine, erythromycin, cocaine, furafylline, cimetidine, dextromethorphan). Exceptions may be made for participants that have received 3 days or less of one of these drugs or substances, if there has been a wash-out 
period before administration of IMP equivalent to at least 5 half-lives of that drug or substance.

22. Use of any therapeutic agents known to alter any major organ function (e.g., barbiturates, opiates, phenothiazines, cimetidine) within 30 days prior to dosing.

23. Use of glucocorticoids within one year prior to dosing.

24. HIV infection with helper/inducer T-lymphocyte (CD4 cell) count of $\leq 300 \times 10^{-6} / \mathrm{L}$. 25. Receiving antiretroviral therapy (ART).

All inclusion and no exclusion criteria must be met. If no single variable/value is outside of the ranges of acceptability, but when multiple values are close to the limits and/or whenever the Principal Investigator has reason to suspect that there might be a health problem (other than tuberculosis), enrolment should only be considered after discussing the case with the sponsor medical monitor. 


\section{Table E2 Definitions of relatedness used to assess adverse events}

\begin{tabular}{|l|l|}
\hline Rating & Definition \\
\hline Unrelated & $\begin{array}{l}\text { A clinical event, including laboratory test } \\
\text { abnormality, for which a clear alternative } \\
\text { explanation exists (e.g., concomitant } \\
\text { medication, concurrent illness), or the details of } \\
\text { which render drug relatedness implausible (e.g., } \\
\text { car accident, unless there is an indication the } \\
\text { drug caused disorientation that may have led to } \\
\text { the event). }\end{array}$ \\
\hline Possibly related & $\begin{array}{l}\text { A clinical event, including laboratory test } \\
\text { abnormality, with a reasonable time sequence to } \\
\text { administration of the drug, which could also be } \\
\text { explained by concurrent disease or other drugs } \\
\text { or chemicals. Information on drug withdrawal } \\
\text { may be lacking or unclear. }\end{array}$ \\
\hline Related & $\begin{array}{l}\text { A clinical event, including laboratory test } \\
\text { abnormality, with a reasonable time sequence to } \\
\text { administration of the drug, unlikely to be } \\
\text { attributed to concurrent disease or other drugs } \\
\text { or chemicals, and which follows a clinically } \\
\text { reasonable response on withdrawal. }\end{array}$ \\
\hline
\end{tabular}

